\title{
JUECES ORDINARIOS Y JUSTICIA CONSTITUCIONAL
}

\author{
RAÚL LETELIER WARTENBERG*
}

RESUMEN: El artículo pretende exponer una crítica a cinco argumentos que han servido para defender la tesis de que los jueces ordinarios pueden inaplicar las leyes en los casos en que estén seguros sobre la inconstitucionalidad de estas.

Palabras clave: Justicia constitucional, jueces ordinarios, Tribunal Constitucional, cuestión de inconstitucionalidad.

ABSTRACT: This article criticizes five arguments exposed by some scholars that support the thesis according to which Chilean courts can refrain to apply statutes when they are convinced about the unconstitutionality of them.

Key words: Judicial review, courts, Constitutional Court, preliminary rules.

\section{INTRODUCCIÓN}

Una parte de la doctrina ha venido sosteniendo de manera constante que los jueces ordinarios tienen la facultad de declarar inaplicables aquellos preceptos legales que se les presenten como "claramente" inconstitucionales ${ }^{1}$. Una vez que entrara en vigor la reforma a nuestra Carta Fundamental de 2005 todo parecía indicar que aquellas razones que motivaban estas posturas se disolverían ante tan contundente cambio constitucional. Sin embargo ello no ha sido así y, más aún, aquella modificación ha revitalizado algunas de esas posturas ${ }^{2}$. El juez ordinario que cree firmemente estar ante una ley inconstitucional, seguirán diciendo estos autores, no se encuentra ahora obligado a plantear la cuestión de constitucionalidad ante el Tribunal Constitucional, sino que puede (y debe) inaplicar directamente aquella ley ${ }^{3}$.

Los argumentos utilizados para defender esta tesis pueden clasificarse de la siguiente manera:

1. Es fácil encontrar en los trabajos de este sector doctrinal una clara preferencia por un sistema de control de constitucionalidad de carácter difuso al estilo del impuesto hoy por su mayor representante: Estados Unidos. Este sistema sería para ellos el que mejor se ajustaría al constitucionalismo moderno, el que mejor respetaría la supremacía de la constitución y el que mejor protegería los derechos fundamentales de las personas. Al contrario, el sistema de control de constitucionalidad concentrado diseñado en Europa vendría a ser, más bien, un sistema afecto a cierta distorsión o enfermedad debida a algunos aspectos negativos presentes en la cultura del Civil Law.

\footnotetext{
* Abogado de la Procuraduría de Punta Arenas del Consejo de Defensa del Estado.

${ }^{1}$ Uno de los trabajos de referencia es el de Lautaro Ríos: Ríos (1988).

2 MARTínez (2006); Ríos (2005c).

${ }^{3}$ MARTínez (2006) p. 465; Ríos (2005c) p. 644.
} 
2. Un argumento de carácter normativo apoyaría además la tesis defendida por este sector. Según expresa el nuevo art. 93 de la CPR, corresponde al Tribunal Constitucional "resolver, por la mayoría de sus miembros en ejercicio, la inaplicabilidad de un precepto legal cuya aplicación en cualquier gestión que se siga ante un tribunal ordinario o especial, resulte contraria a la Constitución”. Esta cuestión -continúa la norma"podrá ser planteada por cualquiera de las partes o por el juez que conoce del asunto".

Según algún autor la redacción de esta norma dejaría claro que la remisión del asunto de constitucionalidad al Tribunal Constitucionalidad sería más bien una opción, esto es, una facultad del juez que conoce el caso concreto. En ningún caso se estaría ante una obligación. Según este supuesto tenor literal y claro de la norma, se concluye que "cuando no exista duda, no hay necesidad de plantear la cuestión. Por ende, si el juez tiene la convicción de que un precepto legal es contrario a la Constitución, a mi entender simplemente no debe

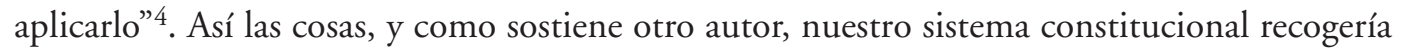
varios sistemas alternativos y compatibles para juzgar la constitucionalidad de las leyes 5 .

3. El tantas veces citado art. 6 de nuestra Carta Fundamental apoyaría también la tesis bajo análisis, toda vez que los jueces -en tanto órganos del Estado- deben someter su acción a la Constitución. De ahí que esta norma les imponga siempre a los tribunales "preferir la Constitución a una norma inferior inconstitucional, cualquiera que esta sea"6.

4. Por otra parte, la tesis defendida no sería más que una confirmación de la situación existente con anterioridad a la reforma. En efecto, aun cuando anteriormente existía un recurso especial denominado recurso de inaplicabilidad, del cual conocía la Corte Suprema, ello no suponía "una especie de monopolio en la aplicación de la Constitución por parte de la Corte Suprema”. Vigente este recurso, las partes podían optar entre plantear este recurso o no hacerlo. Si no lo planteaban -en cuanto garantía establecida en su favor- también podían alegar la inconstitucionalidad ante los propios jueces ordinarios y estos podían inaplicar una ley considerada por ellos como inconstitucional ${ }^{7}$.

5. Ratificaría también esta línea de argumentación el hecho que diversos sistemas comparados harían suya la tesis defendida, es decir, concederían a los jueces la facultad de inaplicar las leyes que estimen inconstitucionales cuando ellos tuvieren certeza de la inconstitucionalidad. El ejemplo paradigmático de esto sería el caso del sistema de judicial review adoptado por la Unión Europea. Lo mismo se predicaría de los casos peruano y colombiano, e incluso, yendo más lejos, de los casos alemán e italiano ${ }^{8}$.

\footnotetext{
${ }^{4}$ Martínez (2006) p. 465.

5 En efectos, tres serían las vías por las cuales declarar la inaplicabilidad de una ley: "a) por los tribunales de instancia, sea en único, primero o segundo grado, según el caso; b) por la Corte Suprema, a través del recurso de casación en Sala; o c) por el Tribunal Constitucional, si se traspasa el conocimiento de la acción de inaplicabilidad, como sería lo apropiado y deseable con respecto a esta”. Ríos (2002) p. 409.

${ }^{6}$ MARTínez (2006) p. 465

7 MARTínez (2006) p. 465-466; Ríos (2002) p. 409.

${ }^{8}$ MARTínez (2006) p. 467. Ríos en este punto es más conservador, pues los ejemplos de derecho comparado que cita no pretenden justificar una determinada interpretación de nuestra Constitución sino que solo sirven para mostrar cómo diversos países practican el control difuso de constitucionalidad de la ley mientras "nosotros, no obstante tener la solución frente a nuestros ojos, seguimos con la errónea creencia que esto sería grave y hasta peligroso". Ríos (2005b) p. 122 y ss.
} 
Creo que los argumentos que apoyan la tesis defendida son erróneos, equívocos y poco convincentes y me propongo demostrarlo en las siguientes líneas. Para ello, abordaré uno a uno estos razonamientos, en el mismo orden en que los he presentado.

\section{EL MARCO GENERAL DE LA JUSTICIA CONSTITUCIONAL}

Uno de los principales errores en la argumentación de aquella parte de la doctrina es el de presuponer que el sistema de control difuso de constitucionalidad, es decir, aquel donde cada órgano al cual se le ha entregado alguna función jurisdiccional puede y debe ser también juez de la constitucionalidad pudiendo sancionar las leyes que la contravengan es el sistema de distribución de la constitucionalidad por excelencia? ${ }^{9}$. Para ellos, este sistema sería el que más garantías entregaría a los ciudadanos, el que mejor protegería el Estado de Derecho y más desarrollaría las ideas del nuevo constitucionalismo ${ }^{10}$. Aquellos sistemas que han optado por concentrar la distribución de la constitucionalidad en jueces específicos constituirían más bien estados intermedios o desviaciones del sistema por excelencia. Esos sistemas concentrados representarían solo "tics" de aquel sistema, generados más bien por la desconfianza que se tiene frente a los jueces ${ }^{11} \mathrm{o}$ serían medios insuficientes para hacer valer la jerarquía constitucional una vez que se constata que pueden "filtrarse" leyes inconstitucionales, ante las cuales el juez ordinario se vería imposibilitado de actuar ${ }^{12}$. O también ese sistema concentrado sería solo un defecto debido a la falta de tradición constitucional de gran parte de los países de Europa continental donde este sistema nace y se expande ${ }^{13}$.

El curso de las argumentaciones que siguen estos autores pretende ser bastante lógico: una vez que se ha reconocido que la Constitución es una norma jurídica y que esta posee una mayor jerarquía que cualquier otra norma del sistema jurídico, parece "evidente" que cualquier juez pueda y deba inaplicar un precepto contrario a ella. ¿Como obligar al juez a desobedecer a la Constitución aplicando reglas que la contradicen?, parecen preguntarse.

Esta línea argumental pretende tener un buen soporte histórico que vendría a sintetizar este gran descubrimiento de considerar a la Constitución norma de normas. Este soporte no puede ser otro que el del nacimiento mismo del sistema de control de constitucionalidad en la esfera norteamericana. Este nacimiento vendría a representar el momento exacto en que se revela y se concreta la idea de la jerarquía de la Constitución. La afirmación de esa jerarquía traerá necesariamente unida, entonces, la idea de un control de la ley por parte de cualquier juez. Quien afirma que la Constitución es la

\footnotetext{
${ }^{9}$ Ríos (2005b) y Ríos (2002). En el mismo sentido, FERNÁNDEZ (2005) p. 116 y ss.

${ }^{10}$ Ríos (2002) p. 418.

11 MARTÍNEZ (2006) p. 459.

12 Ríos (2005b) p.105. Aun cuando contradictoriamente este autor sostenga que el sistema que imperará luego de la reciente reforma a la Constitución será un control "concentrado en un solo órgano supremo, lo que restablece el principio de unidad de jurisdicción en esta delicada materia y pone término a la indeseable dualidad interpretativa, anterior a la vigencia de la reforma...”, Ríos (2005a) p. 76

13 MARTínez (2005a) p. 170.
} 
norma superior -tal como lo habría hecho atrevidamente los EE.UU.- no podría al mismo tiempo obligar a los jueces a que apliquen (que no es otra cosa que ejecutar aquella jerarquía) leyes inconstitucionales ${ }^{14}$.

Pero, ¿es que realmente cuando EE.UU. "inventa” su sistema de judicial review solo pretende realzar el valor normativo de su Constitución y obtener así su irrestricto respeto? ¿Es que solo pretende hacer realmente efectivo aquel contrato social de todos los norteamericanos? ¿Qué hay efectivamente en el origen de este sistema de justicia constitucional?

Como sabemos, el argumento fundacional acerca del comienzo de la revalorización de la Constitución comienza ya a partir de la Constitución de 1787, y, por sobre todo, en su ejecución en el famoso caso Marbury vs Madison. El texto de esta sentencia resulta ser bastante claro cuando indica que "cuando una ley está en conflicto con la Constitución y ambas son aplicables a un caso particular, de modo que la Corte debe decidir ya sea conforme a la ley, desechando la Constitución, o conforme a la Constitución, desechando la ley, debe la Corte determinar cuál de las normas en conflicto gobierna el caso. Esto constituye la esencia misma del deber de administrar justicia. Luego, si los tribunales deben tener en cuenta la Constitución y ella es superior a cualquier ley ordinaria, es la Constitución y no la ley la que debe regir el caso al cual ambas normas se refieren" ${ }^{15}$. Aquella Constitución libertaria y esta sentencia atrevida inaugurarían, así, la era de las constituciones efectivamente respetadas.

La argumentación histórica parece ser entonces bastante razonable. El sistema norteamericano ha sido el que, escriturando su pacto principal y respetándolo realmente, no podía sino entregarle a cualquier juez la posibilidad de ejecutar coactivamente aquellas normas constitucionales, coacción que es la expresión máxima de estar ante verdadero derecho.

Sin embargo, paralela a esta supuesta épica historia de una sociedad dispuesta a que su pacto constitucional sea respetado y a garantizar los derechos de los ciudadanos ${ }^{16}$, existen también otras historias, menos heroicas, menos famosas, menos optimistas acerca del desarrollo de los institutos humanos, pero que, tal vez, muestran más claramente el porqué del nacimiento de esta idea de supremacía constitucional o del por qué de entregar específicamente el poder de judicial review a un grupo de jueces ${ }^{17}$.

No es mi propósito agotar aquí todas aquellas "otras" historias presentes en el desarrollo del constitucionalismo americano. Solo pretendo insinuar la idea de que bajo la entrega a los jueces del poder de judicial review se encontraban también otras razones un poco menos optimistas, pero que explican más eficazmente este interesante fenómeno. Adelantando la conclusión, creo que puede razonablemente sostenerse que detrás del comienzo de la justicia constitucional norteamericana no solo se quería afirmar la supre-

\footnotetext{
${ }^{14}$ Ríos (2002) p. 390 y ss.

155 U.S. 137 (1803).

${ }^{16}$ Tal como la presenta, por ejemplo, Ríos (2002) p. 390 y ss.

${ }^{17}$ Ya indicaba Wood en referencia a la judicial review que "[o]nly the history of the American jurisprudence, only the history of American legal culture as a whole, can explain the development of this extraordinary power". WOOD (1988) p. 1293.
} 
macía de la Constitución, sino que también se quería utilizarla como un eficaz instrumento de opresión a las fuerzas democráticas.

En 1786, un veterano de la guerra de independencia llamado Daniel Shays, organizó una de las más grandes rebeliones antijudiciales de la historia norteamericana. El motivo de esta era evitar que los jueces conocieran las causas que algunos acreedores habían iniciado contra miles de deudores, exigiéndoles el pago de deudas contraídas sin otro afán que hacer frente en común a la guerra de independencia que hace poco terminaba. Una vez lograda la autonomía, aquellos deudores, principalmente campesinos, artesanos u obreros, se encontraban en una situación tanto o más precaria que aquella que habían tenido con anterioridad. Cansados de esa miseria e inestabilidad, aquellos deudores reclamaban continuamente a los legisladores que se tomasen medidas inmediatas para frenar esta verdadera usurpación en manos de los jueces ${ }^{18}$. Sin embargo, esos legisladores, muchos de los cuales representaban solo a las elites norteamericanas, poco les tomaban en cuenta. Ante esta desolación, muchos de esos campesinos y obreros recurrieron a "ocupar" los tribunales para que estos no dieren curso a aquellos “injustos" procesos judiciales ${ }^{19}$.

Si bien muchos de estos levantamientos fueron prontamente acallados, sus consecuencias perdurarían. Tal era la cantidad de deudores y tan justas sus pretensiones que poco a poco los legisladores estatales debieron empezar a atenderlas. Esos mismos legisladores, en efecto, comenzaron a proponer en sus campañas electorales programas de gobierno que consistían casi exclusivamente en medidas tendientes a aliviar los problemas de los deudores ${ }^{20}$. Una vez que se percibió que el incremento de estas demandas populares era problemático, los votos debieron buscarse precisamente en la satisfacción de aquellas necesidades comunes. Por otra parte, la revolución había traído consigo la democratización de las asambleas legislativas de los estados, aumentando sus miembros y variando su componente social. Hombres más humildes y menos instruidos se sentaban ahora en los parlamentos. "En New Hampshire, por ejemplo, en 1765 la asamblea colonial solo contaba con treinta y cuatro miembros, casi todos caballeros acaudalados de la región costera en torno a Portsmouth. En 1786, la Cámara de Representantes del estado había aumentado hasta tener ochenta y ocho miembros. La mayoría de ellos eran granjeros corrientes u hombres moderadamente ricos y muchos procedían de las regiones occidentales del estado" 21 . Serán, entonces, estos nuevos parlamentos los que comenzarán a escuchar los clamores populares, aprobando las controvertidas emisiones de dinero para hacer frente así a la galopante situación de crisis existente.

Estas decisiones, sin embargo, no podían ser percibidas de forma pacífica por la clase de los mercaderes, políticos y grandes propietarios. La clase baja y los mismos deudores se habían apoderado de los parlamentos, y ahora pretendían imponer sus pretensiones a

\footnotetext{
${ }^{18}$ A propósito de ello, escribía el general Henry Knox a Washington que "there creed is, that the property of the United States, has been protected from confiscation of Britain by the joint exertions of all, and therefore ought to be the common property of all". The Papers of George Washington. [en línea] http:// gwpapers.virginia.edu/documents/constitution/1784/madison2.html.

${ }^{19}$ FISKE (1896) p. 177 y ss.

${ }^{20}$ Gargarella (1996) p. 23-24.

${ }^{21}$ WOOD (2003) p. 191.
} 
través de las leyes. La ley y la democracia, banderas de luchas para la elite política y para la clase acaudalada en la era revolucionaria, se habían convertido así, en el nuevo enemigo que había que afrontar. El argumento de las “amenazas a los derechos individuales” y el del "respeto de las minorías" serán ahora el motor de lucha ${ }^{22}$. Estas dos ideas más el retórico argumento de que la soberanía no reside realmente en los representantes sino en el pueblo, harán que, reduciendo la dignidad de la ley, no cueste tanto diseñar un sistema para derrotarlas aun cuando hayan sido aprobadas por la mayoría del Parlamento ${ }^{23}$.

El programa a seguir estaba entonces trazado. Controlar la ley y frenar la democracia. El delegado a la Convención por Massachussetts era bastante explícito cuando indicaba que "los males que experimentamos derivan del exceso de democracia". El mismo Hamilton se manifestaba "contra los vicios de la democracia" y la "sorprendente violencia y turbulencia del espíritu democrático" 24 . Esto será lo que conllevará a que aquella primera constitución esté impregnada de una fuerte división y compensación de poderes. El Poder Legislativo debía ser frenado, sobre todo luego de observar que de forma constante "cuanto más numerosa es una asamblea [legislativa], sean las que fueren las personas que la integren, más fuerte es el ascendiente de la pasión por sobre la razón” ${ }^{25}$. La desconfianza en el Legislativo será, así, una idea matriz en toda la organización constitucional norteamericana ${ }^{26}$.

Para lograr el objetivo propuesto debía idearse un sistema de control de los actos del Parlamento. Se pensó en un órgano especial de revisión compuesto por miembros del Poder Ejecutivo y Judicial, pero la idea no tuvo un gran éxito ${ }^{27}$. Una cosa sí estaba totalmente clara para los participantes en la Convención: los jueces debían tener un rol totalmente protagónico en este control $^{28}$. Diversas son las razones que motivaban esta conclusión. Una razón, sin embargo, normalmente no enunciada, resulta ser especialmente interesante. Los jueces en el siglo XVIII no provienen precisamente de los sectores desposeídos de la sociedad norteamericana. Ellos representan, de cierta forma, a las elites gobernantes y son, para ellas, una excelente forma de controlar, de apaciguar, de aquietar a las masas apasionadas. ¿Dónde se encuentra la aristocracia americana? se pregunta Tocqueville. "La aristocracia americana -concluye- se sienta en el banquillo de los abogados y en el sillón de los jueces"29.

\footnotetext{
22 WOOD (1988) p. 1304 y ss.

${ }^{23}$ WOOD (1999) p. 793-794.

${ }^{24}$ BLANCO (1998) p. 108.

${ }^{25}$ HAMILTON et al. (2004) p. 249.

26 BLANCO (1998) p. 119.

27 WoOd (1999) p. 797; GARGARELLA (1996) p. 39 y ss.

${ }^{28}$ Curiosamente, los jueces no habían sido vistos en la América colonial con muy buenos ojos. De hecho, eran considerados como una verdadera extensión del poder de la Corona, incluso sin la independencia que los mismos jueces británicos podían tener. Esta fue, en efecto, una de las razones para poder neutralizar el poder de los jueces por medio de la institución de los jurados. WOOD (1999) p. 790.

29 Tocqueville (2002) p. 387. "Cuanto más se reflexiona sobre lo que pasa en los Estados Unidos, más se convence uno de que el cuerpo de los legistas forma en ese país el más poderoso y, por así decirlo, el único contrapeso de la democracia"

"En los Estados Unidos es donde se descubre fácilmente cómo el espíritu legalista, por sus cualidades y aun diría que por sus defectos, puede neutralizar los vicios inherentes al gobierno popular".
} 
El control de los actos del Parlamento no surge, entonces, solamente por la afirmación progresiva de la supremacía constitucional, cual victoria de las reglas básicas por sobre los mandatos del Parlamento. Este control es también una toma de posición (con los valores y necesidades presenten en ese momento) acerca de la forma como una sociedad determinada, o más bien, los grupos de poder dominantes en un momento temporal específico, miran la democracia y la forma en que deben coordinarse los intereses de una minoría influyente y de una mayoría supuestamente inculta e inexperta en el arte de gobernar ${ }^{30}$.

El asentamiento de este poder de control no podía, sin embargo, haberse dispuesto en la misma carta constitucional. La otrora desconfianza en los jueces lo impedía, y documentadamente es posible acreditar que los padres fundadores de la Constitución americana no pretendieron insertar en ella un poder tan fuerte como el de judicial review ${ }^{31}$. Sería el silencio de la Constitución el primer paso para la posterior consagración del sistema de control de las leyes de la mano de los mismos jueces, alguna vez cuestionados. No es entonces una casualidad que diversos antiguos diplomáticos y políticos, una vez enfrentados a la opción de elegir sus "futuros trabajos", opten con posterioridad a la Constitución por sentarse precisamente en los sillones de la Corte Supre$\mathrm{ma}^{32}$, y desde allí, más que expertos legales, se consoliden rápidamente como verdaderas autoridades políticas ${ }^{33}$.

El escenario en que nacerá la justicia constitucional en los sistemas jurídicos europeos será, por otra parte, totalmente diverso. Tampoco pretendo aquí enunciar todos los hechos históricos que rodean tanto su construcción como la misma dilación en su implementación. Solo pretendo poner de relieve la importancia de las "dudas estructurales" que dominan su generación.

Como se sabe, en comparación con el sistema norteamericano, el sistema europeo de justicia constitucional nace con un claro retardo. Si bien hay algún germen en algunas constituciones como la suiza de 1874, es recién en la constitución austriaca de 1920 donde el sistema adquiere su forma más característica, posicionándose como el "modelo europeo de justicia constitucional", en oposición al modelo norteamericano.

Una difundida explicación de la tardanza en asumir un sistema de control de constitucionalidad la conecta con aquella imagen que muestra a Europa sumida en una monarquía sin límites, un poder estatal soberano que pisoteaba día a día los derechos de

\footnotetext{
"Cuando el pueblo americano se deja embriagar por sus pasiones o se entrega con arrebato a sus ideas, los legistas le ponen un freno casi invisible que lo modera y lo contiene. A sus impulsos democráticos oponen secretamente sus propias tendencias aristocráticas; a su amor por la novedad, su respeto supersticioso por lo antiguo; a la inmensidad de sus designios, la estrechez de sus puntos de vista; a su desprecio por las reglas, su amor por las formas, y a su prisa, su hábito de proceder con lentitud".

"Los tribunales son los órganos más visibles de que se sirve el cuerpo de legistas para actuar sobre la democracia”. TOCQUEVILLE (2002).

30 WOOD (1999) p. 809.

31 WOOD (1999) p. 796-797.

32 WOOD (1999) p. 803.

33 WHEELER (1973) p. 123-158.
} 
un pueblo insatisfecho ${ }^{34}$. Sin embargo, junto a esta interpretación bastante recurrente, es posible examinar cómo esta tardanza en asumir un sistema de control de constitucionalidad se debió no a un mero retraso en la protección de los derechos fundamentales ni puede tacharse simplemente como una manifestación de una época oscura del constitucionalismo. En efecto, no era el desconocimiento del sistema de judicial review lo que motivaba su no adopción en la órbita europea. De hecho, este mecanismo había despertado la curiosidad de los juristas europeos desde los primeros momentos ${ }^{35}$. El rechazo al sistema de judicial review norteamericano por parte de Europa fue, en realidad, un rechazo meditado, consciente y razonado ${ }^{36}$. La razón medular del rechazo consistía en que asumir este tipo de control significaba alzar al Poder Judicial por sobre los demás poderes del Estado quebrantando de esta forma el equilibrio de poderes. Europa, al contrario de lo que se piensa, conocía claramente muchos de los motivos y vicios que ocasionaron la creación del sistema norteamericano de control de las leyes y era este preciso conocimiento el que le impedía adoptarlo.

Prontamente, los autores europeos entendieron que de ninguna manera la judicial review podía derivarse del mero entendimiento de los tribunales como entes detentadores de jurisdicción. Entregar este control a los jueces era concebir un poder nuevo, y, del mismo modo, crear una nueva distribución de poderes. Esa nueva posición traería necesariamente una confrontación entre los tribunales y los poderes de composición democrática. El centro de la discusión, entonces, no era la pregunta acerca del por qué del control sino más bien la del por qué los jueces ${ }^{37}$.

Así las cosas, junto con el surgimiento de la judicial review aparece la resistencia europea frente a este mecanismo en tanto desestabilizador del equilibrio de poderes. ¿Es realmente la concesión del poder de supresión de leyes al Poder Judicial la manera más eficaz de proteger los derechos individuales? ¿Es realmente justificable este deterioro en las bases democráticas bajo el pretexto de defender la Constitución?, parecían preguntarse continuamente los juristas europeos. Precisamente esta constante duda o la incertidumbre sobre las respuestas a estas cuestiones será una de las razones principales de la tardía asunción europea del sistema de control de las leyes.

La historia irá dando respuestas diversas a esas dudas y así se irá decantando la construcción del posterior sistema europeo de control de las leyes. La primera de las preguntas se resolverá privilegiando la figura no específicamente judicial, pero sí de un tercero imparcial que sirva de custodio de la Constitución. Diversas razones apoyarán esta opción. Dentro de las más importantes está la necesidad de los estados federales de definir los marcos de competencia que las constituciones crean. El problema de la primacía de las normas federales por sobre las de los Länder será uno de los principales problemas en la gestación de la Constitución austriaca. Una de las posiciones abogaba por una igualdad de ambas normas, donde solo la más nueva prevaleciere a la más

\footnotetext{
${ }^{34}$ MARTíneZ (2005a) p. 149-171.

35 AHUMADA (2005) p. 246.

36 El desarrollo del sistema europeo de control de constitucionalidad posee también su propio curso histórico, incluso anterior a la Constitución austriaca de 1920. CARAVITA (1985) p. 29 y ss.

37 Ahumada (2005) p. 250.
} 
antigua. Esta disfuncional respuesta generó rápidamente una fuerte oposición ${ }^{38}$. Eran muchos los que, reclamando la primacía de las leyes federales, abogaban por la creación de un tribunal que resolviera los conflictos entre leyes. " $[\mathrm{N}] \mathrm{o}$ resulta excesivo afirmar -sostenía Kelsen- que la idea política del Estado federal no se encuentra plenamente realizada sin la institución de un tribunal constitucional" 39 . Esta prevalencia ya había sido introducida, por lo demás, tímidamente al ordenamiento austriaco con la Ley Constitucional de Representación popular de 1918 por la cual se había instituido un control previo de competencia legislativa de los Länder. De ahí que en la formulación de la Constitución austriaca de 1920 el tema de una jurisdicción constitucional estará empapado de la discusión sobre los conflictos competenciales ${ }^{40}$, tema de enorme importancia, toda vez que con él se trazan los rasgos esenciales de la distribución del poder entre los estados y federación. Será precisamente esa discusión de implementación del modelo federal la que decantará en el famoso art. 140 de la Constitución austriaca de 1920, con el cual se entrega a un tribunal constitucional el conocimiento de la inconstitucionalidad de las leyes del Land a petición del gobierno federal (reconocimiento tácito de la primacía del derecho federal) y la inconstitucionalidad de las leyes federales a instancia de un gobierno de los Länder (cláusula de transacción ${ }^{41}$, por la cual estos Länder se aseguran cierto control a la federación $)^{42}$.

La posterior caída del orden democrático será preparada en parte por el fenómeno de depreciación en la custodia constitucional que comienza a partir de 1933 cuando se inicia el desmantelamiento y desactivación del Tribunal Constitucional austriaco. Los hechos que suceden a este período son ya por todos conocidos. La crisis de los sistemas jurídicos, valóricos y sociales desencadenará el quiebre total de la sociedad europea y su autodestrucción masiva.

Con posterioridad a la II Guerra Mundial, la necesidad de una justicia constitucional se hará más viva que nunca. El imperioso requerimiento de no volver a tener aquella clase de gobiernos autoritarios hará necesaria una entrega más fuerte de la custodia del pacto constitucional a un tercero imparcial. Ello traerá consigo que los juristas europeos vean con otros ojos lo que sucedió y seguía sucediendo en los

38 CRUZ (1987) p. 240.

39 KELSEN (1928) p. 253. "Plus que nulle part ailleurs, le besoin se fait ici sentir d'une instance objective qui décide ces luttes [de competencias entre estados y federación] de façon pacifique, d'un tribunal devant lequel ces litiges puissent être portés comme des problèmes d'ordre juridique, et décidés comme tels - c'està-dire d'un tribunal constitutionnel...”. KELSEN (1928) p. 254.

${ }^{40}$ CRUZ (1987) p. 251 y ss.

41 Otro de los factores que motivó la creación de este sistema de justicia constitucional fue el profundo conflicto que veían venir los partidos políticos austriacos con posterioridad a la I Guerra mundial. Este conflicto ideológico requería urgentemente la existencia de un órgano que descomprimiera la tensión entre ellos.

42 Cabe indicar que esta impugnación puede realizarse en cualquier momento, es decir, aún (y especialmente) cuando la norma ha entrado en vigencia, y el efecto de su acogimiento es la derogación de la norma legal. Es precisamente la naturaleza y relevancia de esta derogación, o anulación en términos de Kelsen, la que lo lleva a referirse al poder del Tribunal Constitucional como una función de legislador negativo. KELSEN (1928) p. 224-225. 
EE.UU. en materia de judicial review ${ }^{43}$. Sin embargo, también ello significará una reactivación de los estudios acerca del mejoramiento del sistema europeo de justicia constitucional.

Por otra parte, eran también conocidos en Europa los excesos que había cometido la Corte Suprema norteamericana en la llamada crisis del New Deal. En esta crisis, la corte había mostrado claramente cómo podía imponer una específica concepción liberal para proteger ciertos intereses económicos afectados por leyes federales de marcado carácter social ${ }^{44}$. Aquella concepción incidió en forma específica en la legislación dictada por el presidente Roosevelt, declarando inconstitucionales diversas normas que componían su programa político (New Deal). Una vez reelegido por una mayoría abrumadora, amenazó al tribunal con un programa que implicaba su propia reforma (Court Packing Plan), lo que hizo que este cambiara su actitud y restringiera al máximo su posición liberal ${ }^{45}$. Había sido así superado este impasse entre la Corte Suprema y el poder político, mas se habían exhibido claramente los escasos límites al poder de los jueces y su potente capacidad de intromisión en las decisiones democráticas.

Este cúmulo de acontecimientos llevará a los europeos a retomar los estudios para poder generar un mejor y más eficiente control a la actividad del Parlamento. Así las cosas, la pregunta acerca de si realmente es justificable el deterioro de las bases democráticas bajo el pretexto de defender la Constitución requería una respuesta urgente. Sin embargo, esta respuesta no podrá contestarse positivamente en orden a importar totalmente el modelo norteamericano. La perspectiva europea de lo que se entiende por democracia no calzará con la judicial review. En este tema, la solución americana será claramente el antimodelo ${ }^{46}$.

Un difundido y lúcido artículo de Hans Kelsen mostrará las desventajas de asumir el sistema norteamericano y la superioridad de un sistema como el austriaco ${ }^{47}$. El desorden y la inseguridad jurídica que provoca el hecho que diversos aplicadores del derecho puedan juzgar la constitucionalidad constituían un aspecto intolerable en una posible

43 Cappelletti y Adams (1966) p. 1207. Como dice Kelsen, "it was especially the experience of the constitutional practice in the United States which influenced the regulation of this question in the Austrian Constitution”. KELSEN (1942) p. 194.

${ }^{44} \mathrm{Y}$ esto a través de una discutible interpretación de la cláusula del debido proceso como "debido proceso sustantivo y económico" (economic substantive due process). Utilizando esta construcción, se sostuvo en el caso Smyth v. Ames (169 U.S. 466) "que las tarifas de ferrocarriles fijadas por los Estados estaban sujetas a control judicial para comprobar si había ferrocarriles en los que se privara de propiedad arbitrariamente”. La misma idea, con mayor fuerza, y más crítica, se desarrolló en el caso Lochner v. New York (198 U.S. 45$).$ En él "se planteaba la constitucionalidad de una ley que reducía el horario laboral de los empleados en las panaderías a sesenta horas semanales y diez horas diarias, el Tribunal declaró la inconstitucionalidad de la ley alegando que esta vulneraba la libertad contractual en forma arbitraria y que por tanto no podía compatibilizarse con la cláusula de debido proceso". DORADO (1997) p. 12.

45 Así, en 1937 (un año después de la reelección de Roosevelt) el tribunal consideró en el caso West Coast Hotel v. Parrish (300 U.S. 397) que "la libertad de contratar no es ilimitada y que las consideraciones legislativas de bienestar público justifican restricciones de la misma”. DORADO (1997) pág. 13.

46 Ahumada (2005) p. 257.

47 KELSEN (1942). Sobre las aportaciones de Kelsen al modelo austriaco de justicia constitucional CARAVITA (1985) p. 57 y ss. 
implantación del sistema norteamericano en Europa ${ }^{48}$. Por otra parte, y debido a la función política y legislativa que desarrollan los jueces constitucionales existía una clara deficiencia democrática en la designación de estos jueces en el sistema estadounidense. Este problema será resuelto por la Constitución austriaca, en la cual los jueces constitucionales serán designados precisamente por las cámaras del Parlamento ${ }^{49}$. Finalmente, diversos problemas de carácter procesal, como la misma legitimación para activar un procedimiento de judicial review, serán resueltos satisfactoriamente por el sistema austriaco, mientras que para el sistema norteamericano seguirán siendo lagunas ${ }^{50}$. De esta forma, Kelsen pretende ofrecer "soluciones austriacas para problemas de los que los americanos no parecen ser conscientes, algunos de los cuales ni siquiera ven como problemas" 51 .

El éxito a nivel europeo de la fórmula kelseniana fue absolutamente rotundo. La construcción del modelo austriaco era la respuesta "más perfecta" a las preguntas que los juristas europeos se hacían en relación a la forma con la cual organizar el control a las leyes. Este sistema sintetizaba así perfectamente la necesidad de controlar al Parlamento, respetar la democracia y proteger la seguridad jurídica.

La relación entre este modelo y el principio de la jerarquía normativa de la constitución también encontraría aquí el mejor equilibrio. Así lo expone acertadamente Cruz Villalón cuando afirma que "[l]o que caracteriza al "sistema europeo" tal como queda plasmado a partir de 1920, antes y por encima de cualquiera de sus conocidos elementos integrantes, es el haber hecho del control de constitucionalidad de las leyes una función regulada, positivizada, racionalizada y, en definitiva, limitada. Frente a la vigencia en principio ilimitada del principio de primacía de la Constitución, tal como de hecho lo entienden e interpretan los tribunales, en el "sistema europeo" es el legislador, normalmente constituyente, el que determina cuáles son exactamente las consecuencias que para las leyes se van a derivar del principio de primacía de la Constitución: cuál es el contenido y alcance efectivos del principio, por quién y ante quién puede ser invocado, con qué consecuencias" 52 .

Esta idea de un control y un principio de supremacía regulados y racionalizados será la que se expandirá rápidamente tanto a diversos países europeos como a países latinoamericanos, entre ellos, el nuestro.

Como hemos podido examinar, los sistemas norteamericano y europeo representan dos respuestas diversas a las preguntas de cómo estructurar un modelo político y jurídico más eficaz y eficiente en la tarea de proteger los derechos fundamentales, defender la

\footnotetext{
48 KELSEN (1942) p. 185-186. Este problema es generado, en gran parte, debido a que los sistemas basados en el derecho romano carecen de stare decisis y, por ende, las decisiones de los tribunales superiores no tienen fuerza vinculante para los tribunales inferiores en casos similares. De ahí que el sistema norteamericano - poseedor de este elemento- pueda paliar aquella inseguridad jurídica e incerteza que un sistema de control difuso podría generar en países europeos. CAPPELLETTI y ADAMS (1966) p. 1215.

${ }^{49}$ KeLSEN (1942) p. 186-187.

50 KeLSEN (1942) p. 193

51 AHUMADA (2005) p. 283.

${ }^{52}$ CRUZ (1987) pp. 32-33.
} 
Constitución, garantizar la estabilidad de las relaciones públicas y privadas y organizar debidamente los poderes públicos. No parece acertada, así, una argumentación que entienda al modelo europeo solo como un defecto del norteamericano. Ambos sistemas han ensayado soluciones diversas para equilibrar las necesidades involucradas en la decisión acerca de cómo debe realizarse el control a los actos legislativos. Cada uno son creaciones derivadas ya de sus propias historias ya de las necesidades que pretenden satisfacer. Ambos han querido definir a su manera y con su historia la medida de síntesis entre la dignidad democrática de las decisiones legislativas y el antiguo temor a nosotros mismos.

\section{LA REGULACIÓN DE LA CUESTIÓN DE CONSTITUCIONALIDAD EN CHILE}

Otro de los argumentos indicados para apoyar la tesis de la competencia general de los jueces para declarar la inaplicabilidad de las leyes se encontraría en la actual redacción del art. 93 CPR. Dicha norma establecería, según ellos, solo una opción -no un deberpara los jueces ordinarios de elevar el asunto al Tribunal Constitucional cuando consideren que una ley que deben aplicar es inconstitucional. Dicha norma no indica que la cuestión de inconstitucionalidad deberá ser planteada, sino que solo expresa que ella "podrá" ser planteada por el juez o las partes. En tanto opción, cuando los jueces estén "seguros" de esa inconstitucionalidad, podrán entonces declararla sin más dilación.

Este argumento literal es sumamente débil. Como sabemos, el verbo "poder" es ambiguo toda vez que con él podemos referir tanto una idea de competencia o poder, a una idea de permisibilidad como también a una de posibilidad. Sin embargo, así como las palabras varían de sentido según el contexto en que se encuentran, también esas palabras varían según el contexto normativo en que se presentan. En el lenguaje constitucional el uso del verbo poder está orientado normalmente a conferir poderes, competencias o legitimaciones y no a entregar opciones o alternativas. Así y específicamente en el art. 93 el uso de la expresión podrá no esta referido a una opción de los jueces sino que a un poder o más bien a una legitimación entregada tanto a los jueces como a las partes para interponer la cuestión. Idéntico sentido puede ser encontrado en el mismo artículo cuando hace referencia al caso del No 5 cuando indica que "[e]n el caso del número $5^{\circ}$, la cuestión podrá promoverse a requerimiento del Senado o de la Cámara de Diputados" enunciando que son estos los legitimados para promover el requerimiento. Lo mismo sucede cuando se hace referencia al caso del No 8. Por otra parte si el uso del verbo "podrá" se refiriese a una opción para el juez de plantear el asunto al Tribunal Constitucional o no hacerlo e inaplicar la ley habría que preguntarse cuál seria el efecto del verbo respecto de las partes, pues la norma indica que tanto el juez como las partes “podrán” plantear la cuestión. Si para el juez implica una opción, ¿qué implica entonces para las partes? ¿También una opción de plantear el asunto al tribunal o desobedecer derechamente la ley? Obviamente esto carece de sentido.

Así las cosas, la única interpretación coherente del art. 93 CPR es que este establece una legitimación tanto al juez como a las partes para interponer la cuestión de constitucionalidad. A ambos entrega un poder de impugnación. 
En tanto norma que atribuye una competencia obviamente no prohíbe las competencias que no entrega, es decir, existiendo otra norma constitucional que habilitase a los jueces para declarar la inconstitucionalidad de las leyes ambas serían igualmente válidas. Pero como sabemos esta última competencia no existe y por ende el único poder que los jueces tienen en esta materia - de la misma forma que las partes- es el de ser legitimados para impugnar las leyes ante el Tribunal Constitucional.

Sin embargo, además de estas razones eminentemente formales, aceptar una interpretación como la propuesta por esta parte de la doctrina conllevaría desvirtuar completamente todo nuestro sistema de justicia constitucional. Y ello por varias razones:

1. Aquella interpretación iría totalmente en contra de lo pretendido con las modificaciones constitucionales. Como indicó el mismo proyecto con el que se inician las reformas de 2005, lo que se pretendió fue "transferir el recurso de inaplicabilidad de la Corte Suprema al Tribunal Constitucional, dando vida con ello a una jurisprudencia constitucional especializada y uniforme" 53 .

Esta pretensión de especialización y uniformidad escasamente se lograría si cualquier juez pudiese inaplicar un precepto que, a su propio entender, considerase inconstitucional.

2. La tesis que atacamos se encontraría, además, en contra de toda nuestra tradición constitucional. Como bien sabemos, a lo largo de nuestra historia como República, nunca hemos evaluado positivamente entregar una facultad de inaplicación de las leyes de manera general a todos los jueces.

En efecto, ya bajo el imperio de la Constitución de 1833, encontramos presente en el debate público el problema de si los tribunales ordinarios pueden inaplicar leyes, más aún cuando aquella Constitución nada decía a propósito de ese control. Sin embargo, aún con esta omisión, la Corte Suprema tuvo una clara tendencia a considerar que los tribunales no tenían competencia para inaplicar preceptos legales ${ }^{54}$. La doctrina, por su parte, era todavía más uniforme en esta visión ${ }^{55}$.

53 Boletín No 2.526-07. Proyecto de reforma constitucional, iniciado en moción de los HH. Senadores señores Chadwick, Díez, Larraín y Romero, que modifica la composición y atribuciones del Congreso Nacional, la aprobación de los tratados internacionales, la integración y funciones del Tribunal Constitucional y otras materias que indica.

54 Bertelsen (1969) p. 135 y ss. Cita este autor un dictamen evacuado el 27 de junio de 1848 por la Corte Suprema donde esta señala que "el Tribunal observará que ninguna Magistratura goza de la prerrogativa de declarar la inconstitucionalidad de las leyes promulgadas después del Código Fundamental y de quitarles, por este medio, sus efectos y su fuerza obligatoria. Este poder, que por su naturaleza sería superior al del Legislador mismo, puesto que alcanzaba a anular sus resoluciones, no existe en Magistratura alguna, según nuestro sistema constitucional”.

55 Así, indicaba sólidamente Huneeus que "[1] os Tribunales llamados a juzgar las causas civiles y criminales han de hacerlo con arreglo a las leyes, puesto que su deber y su misión es aplicarlas en las controversias de que conocen. De aquí se infiere que, llamados a fallar un negocio, no pueden dejar la ley sin aplicación, aun cuando, a juicio de ellos, fuera inconstitucional; así como el Presidente de la República tampoco podría dejar sin ejecución una ley, porque él la conceptuase contraria a la Carta Fundamental. La Constitución califica este acto como delito, en su artículo 92 (83), respecto de los Ministros, y en ninguna parte confiere semejante atribución a los Tribunales, pues ella los haría Jueces del Congreso mismo y les suministraría un medio fácil de hacer nugatorias e ineficaces las leyes, so pretexto de reputarlas como inconstitucionales. El Poder Judicial no es Juez de la Ley; ha sido creado para aplicarla, sea ella buena o mala”. HUNEEUS (1891) pp. 238-239. 
En el marco de la gestación de la Constitución de 1925, diversas ideas del constitucionalismo irán adquiriendo nuevas perspectivas. Nacerá, así, un acuerdo más o menos generalizado en torno a concretar de manera efectiva un control de constitucionalidad de las leyes. Sin embargo, al lado de este acuerdo -y tal como lo fue en Europa- también está presente el temor de descompensar el equilibrio de poderes o de producir un perturbador estado en donde todo tribunal pudiere inaplicar cualquier ley ${ }^{56}$. Esta unión de pretensiones, junto a los deseos de no dilatar los procesos judiciales y de evitar -ante la dignidad de la ley- los efectos generales de las sentencias de inconstitucionalidad, fue la que selló el acuerdo definitivo de asignarle a la Corte Suprema, de manera privativa, la facultad de control constitucional, de la misma forma como se generaron los acuerdos de justicia constitucional en el ámbito europeo ${ }^{57}$. Sus decisiones solo tendrían efectos particulares y se desenvolverían en un procedimiento accesorio al asunto principal antes de que se hubiese dictado sentencia en este último.

Vigente la Constitución de 1925 , se vuelven patentes dos necesidades. La primera es la inexistencia de una autoridad que resuelva los conflictos entre el Poder Ejecutivo y el Congreso. Ya lo indicaba en 1969 el Presidente Frei Montalva cuando expresaba que muchos de esos conflictos eran superados por vías políticas "[p]ero el problema se presenta cuando estos acuerdos no se obtienen, porque nuestro sistema no prevé el medio para zanjar la disputa. Una reforma constitucional ha de llenar este vacío" 58 . La segunda aparece luego de la divulgación de las experiencias extranjeras sobre el control de constitucionalidad y se concretiza en el imperativo de examinar de manera general esa constitucionalidad de las leyes ${ }^{59}$.

La forma de hacer frente a estas necesidades es crear un Tribunal Constitucional, lo que finalmente se hace en 1970 por medio de las modificaciones introducidas por la Ley No 17.284. Su estructura, composición y facultades son bastante conocidas, ya que la Constitución de 1980 las conservó en gran parte. En lo que nos interesa, nuestro sistema de justicia constitucional quedaba definido como un "sistema concentrado pero con dualidad de judicatura" 60 toda vez que la distribución de la constitucionalidad en las opciones legislativas era desarrollada tanto por la Corte Suprema cuando conocía del recurso de inaplicabilidad de las leyes, como por el Tribunal Constitucional cuando conocía de la constitucionalidad de los proyectos de ley.

\footnotetext{
56 BERTELSEN (1969) p. 138-139. además el desarrollo de la discusión en SAENGER (2003) p. 409 y ss.

57 No son así solo "fantasmas" o "temores paralizantes" como define Ríos a todos estos argumentos que van en contra de asumir el modelo norteamericano de control difuso. Ríos (2002) p. 396 y ss.

58 Citado por ZÚNigA (2002) T. II, p. 43.

59 Zúñiga cita a las Terceras Jornadas de Derecho Público como un momento en el cual la doctrina iuspublicista de 1964 reclama la creación de un Tribunal Constitucional al cual se le otorguen las facultades de "a) el control preventivo de la constitucionalidad de los proyectos de ley o indicaciones a dichos proyectos, a petición del Presidente de la República o de cualquiera de las Cámaras, y b) el control, con efecto absolutos de la constitucionalidad de todas las leyes, tanto respecto de su contenido (inconstitucionalidad de fondo) cuanto el procedimiento de formación de la ley (inconstitucionalidad de forma)". ZÚNIGGA (2002) T. II, p. 42-43.

${ }^{60}$ ZÚNIIGA (2002) T. II, p. 60
} 
3. Como sabemos, la cuestión de constitucionalidad de que conoce el Tribunal de conformidad al art. 93 No 6 CPR puede llegar al Tribunal ya sea a petición de parte o elevarse de oficio por el juez. En el caso que sea de oficio por el juez, cabe preguntarse en qué momento podrá darse la posibilidad de que ese juez envíe la pregunta de constitucionalidad al Tribunal, es decir, qué presupuestos deben concurrir para que el juez decida elevar el asunto. La respuesta a esta pregunta no puede ser otra que cuando el juez considere que una norma que debe aplicar a un caso determinado resulta ser inconstitucional aun cuando ninguna parte se lo haya hecho valer. Si esto es efectivo, resultaría entonces absurdo que para el caso en que una parte haga valer ante el juez la inconstitucionalidad de una ley este pueda inaplicarla directamente, pero cuando esa inconstitucionalidad se le revele solamente a él, no pueda hacerlo pues este será el preciso caso por el cual procederá elevar la cuestión de constitucionalidad de oficio. Esta es la única forma de entender el supuesto "de oficio" contemplado en la norma; interpretar que en estos casos el juez debe inaplicar en forma directa sería dejar sin efecto y al mismo tiempo vulnerar la disposición constitucional en cuestión.

En efecto y a mayor abundamiento, el mismo art. 93 exige, tanto al juez que eleva la cuestión como a las partes, que la impugnación esté "fundada razonablemente", esto es, no se exige del tribunal ordinario meras dudas acerca de la constitucionalidad, sino que se exige una cuestión fundada en donde este tribunal -tal como sucede actualmente en Alemania- presente al Tribunal Constitucional con claridad y con argumentos fundados la inconstitucionalidad de la ley que cuestiona ${ }^{61}$. La solución es entonces evidente; cada vez que se quiera inaplicar una ley inconstitucional sea a petición de parte o por convencimiento de juez, esa inaplicabilidad solo podrá resolverse por el Tribunal Constitucional.

4. Finalmente otro argumento contradeciría la tesis analizada. De conformidad a la Constitución, la petición de inaplicabilidad debe ser presentada directamente al Tribunal por las partes en el juicio y no al juez que conoce del caso concreto. De aceptar que el juez ordinario puede inaplicar un precepto legal cuando tenga certeza de su inconstitucionalidad ello importaría un contrasentido con la posibilidad de las partes de plantear directamente la inaplicabilidad al Tribunal Constitucional. En efecto, de suponer lo indicado, lógico habría sido que las partes presentarán su recurso ante el juez ordinario para que este "solo en caso de dudas" elevase la cuestión al Tribunal Constitucional. Pero como sabemos, eso no fue así. El hecho de que las partes puedan presentar directamente su recurso ante el Tribunal Constitucional revela la decisión de que sea este el único órgano competente para declarar la inaplicabilidad.

${ }^{61}$ El actual proyecto que modifica a Ley Orgánica del Tribunal Constitucional (Boletín 4059-07) es claro al exigir que el requerimiento de inconstitucionalidad que realizan tanto el juez como de las partes deberán contener "una exposición clara de los hechos y fundamentos de derecho en que se apoya, la indicación del o de los vicios de inconstitucionalidad que se aducen, con indicación precisa de las normas constitucionales que se estiman transgredidas". En efecto, el Tribunal Constitucional rechazará los requerimientos judiciales si estos carecen de fundamento plausible y así lo declarará en su sentencia, la que deberá comunicarse a la Corte Suprema para los fines que sean pertinentes. 


\section{LA PARADOJA DEL ART. 6 DE LA CPR}

Una vez más el art. 6 de la CPR sirve, en la fundamentación de la tesis criticada, para afirmar que, debido a que los jueces ordinarios deben respetar la Constitución, ello les impone preferirla por sobre cualquier otra norma jurídica del sistema ${ }^{62}$.

El art. 6 de nuestra carta es una norma curiosa. Como se sabe, esta norma ha valido para que algunos autores se sirvan de ella para justificar, por ejemplo, una nulidad de derecho público imprescriptible ${ }^{63}$, la imposibilidad de la invalidación de actos administrativos $^{64}$ o incluso una responsabilidad del Estado de carácter objetiva ${ }^{65}$. Es decir, instituciones o decisiones jurídicas de tan alto nivel y de tan fuerte contenido social como estas se sustentan en este supuestamente contundente artículo 6.

Frente a esto, vale la pena enunciar una interesante paradoja. Dicho artículo 6 dispone que "[l] os órganos del Estado deben someter su acción a la Constitución y a las normas dictadas conforme a ella, y garantizar el orden institucional de la República”. Del mismo modo indica que "[l]os preceptos de esta Constitución obligan tanto a los titulares o integrantes de dichos órganos como a toda persona, institución o grupo". "La infracción de esta norma generará las responsabilidades y sanciones que determine la ley”. Del tenor de esta norma surge la siguiente pregunta ¿Qué sucedería si esta norma no existiese en la Constitución? Y la paradoja es que creo que si esta norma, tan fundamental como se dice y que sirve de supuesto fundamento a tan grandes instituciones, no estuviese en la Constitución, no sucedería absolutamente nada, es decir, el ordenamiento jurídico nacional no perdería nada de su contenido normativo.

En efecto, el contenido del art. 6 solo se encarga de expresar la "fuerza normativa" de las disposiciones constitucionales, es decir, que esas normas obligan a sus destinatarios (Estado y toda persona, institución o grupo, es decir, a todos) a hacer lo que en ellas se indica. Nada más inherente a la idea de norma que esto que aquí se enuncia. Y tan inherente a esta idea normativa, que su expresión formal no resulta ser hoy necesaria. Su explicación es, por un lado, retórica a objeto de enfatizar que estamos ante una norma jurídica y de que hay una obligación de respeto y, por otro, histórica en cuanto pretende afirmar el carácter de norma jurídica de la Constitución versus anteriores interpretaciones que la veían solo como un documento programático ${ }^{66}$.

Hoy, no obstante, percibida socialmente la Constitución como una norma jurídica, no resulta ser necesaria una disposición de estas características. De hecho, muchas constituciones no contienen una norma similar ${ }^{67}$, y no creo que razonablemente pudiese decirse que esas constituciones no deben ser obedecidas, o que aquellos países consideran sus constituciones como meros programas.

\footnotetext{
${ }^{62}$ Ríos (2002) pp. 401 y ss.; MARTíneZ (2006) p. 465. En el mismo sentido, FERnÁNDEZ (2005) pp. 116 y ss.

63 Soto (2000) pp. 55-62, Fiamma (1991) pp. 91-98.

64 SOTO (1988) pp. $157-167$.

65 SOTO (1996) T. II, pp. 308

66 GARCÍA de ENTERría (2006) pp. 47 y ss.

67 Solo a modo de ejemplo, dicha cláusula no se encuentra en constituciones como la de EE.UU., Alemania, Francia o Italia.
} 
Sin embargo, y dejando este argumento de lado, aún entendiendo que este artículo posee un contenido normativo especial, cual es, la concepción de la supremacía constitucional, incluso en ese caso, como excelentemente lo ha mostrado Atria, dicha supremacía no puede justificar que todo juez (o todo funcionario) pueda declarar la inconstitucionalidad de una regla ${ }^{68}$.

En efecto, creo que el mecanismo creado para apreciar la legalidad o la constitucionalidad de una norma, y con el cual se explica la concesión a determinados tribunales de la competencia para distribuir tanto aquella legalidad como la constitucionalidad, funciona de la siguiente forma:

La Constitución, en tanto acuerdo fundacional, posee evidentemente una jerarquía mayor a todas las demás decisiones, toda vez que ordenará la forma misma de adoptar esas decisiones futuras. Todas las demás normas y actuaciones, cuya validez depende del cumplimiento del procedimiento establecido en la Constitución, deben ser consideradas nulas si es que no la respetan. Leyes, actos administrativos, sentencias judiciales estarán sujetas a esta "regla sistémica de validez".

Esta regla sistémica de validez se construye a partir de un concepto absoluto o, más bien, de un presupuesto necesario del sistema jurídico, cual es la negación general de validez para los casos de contravención al derecho. El enunciado podría indicarse así:

(A) Toda norma contraria a derecho es nula. Este tipo de norma tiene la misma morfología que otras reglas que pudiesen operar al interior de otros sistemas como la que indica que "toda ley injusta no es ley".

Sin embargo, además de esta forma de expresar la idea de nulidad, comúnmente utilizamos otro enunciado para hacer referencia a la nulidad para un caso determinado. Así:

(B) La norma X es nula.

En este caso, en cambio, el enunciado "nula" contiene un concepto esencialmente relativo ${ }^{69}$, toda vez que la apreciación de validez requiere una asignación de sentido a la norma de contraste y a la contrastada, y el desarrollo de una operación de confrontación de suyo compleja, de manera que los resultados de este test podrán variar considerablemente de un operador jurídico a otro ${ }^{70}$.

El enunciado (A) es indiscutible dentro del sistema que lo genera, toda vez que viene a representar una verdadera regla de sustento de las demás. El enunciado (B), por su parte, hace referencia a una idea de nulidad que, en tanto relativa, es pragmáticamente ambigua. En efecto, este juicio puede ser pronunciado ${ }^{71}$ :

a) Por el juez que conoce de la legitimidad de una determinada norma, ya sea para convalidar o "invalidar" aquella norma.

b) Por el abogado o por un jurista dogmático para proponer al juez que conoce de la legitimidad de la norma la convalidación o invalidación de ella.

\footnotetext{
68 ATRIA (2003) p. 321.

69 KELSEN (1984) pp. 202 y ss.

70 Más todavía si se entiende que los operadores jurídicos incorporan en sus razonamientos de contraste argumentaciones de moral personal. Véase, por ejemplo, Ross (1994) pp. 133 y ss.; WRÓBLEWSKI (1981) pp. 604-626.

71 Sigo en parte a GUASTINI (1992) p. 199.
} 
c) Por el jurista que describe empíricamente un ordenamiento para constatar que el hecho que un juez ha convalidado o invalidado un norma determinada.

d) Por cualquier persona al expresar su propio juicio de contraste respecto a una determinada norma.

Diversas personas pueden, entonces, realizar este test de legalidad o constitucionalidad.

Si miramos, por ello, al ordenamiento jurídico desde esta perspectiva, se puede concluir que no resulta posible afirmar un conocimiento del conjunto objetivo de normas válidas de aquellas que aparecen como existentes en un determinado sistema jurídico, toda vez que cada operador podrá dibujar su propio sistema de normas válidas ${ }^{72}$ de conformidad a su propia asignación de sentido ${ }^{73}$. Esta incerteza o ambigüedad pragmática en la idea de validez es la que exige la identificación de órganos determinados que, a través de decisiones institucionales, fijen aquellos juicios de contraste como nuevas normas particulares, con eficacia jurídica y validez general ${ }^{74}$. La ambigüedad termina, así, con una decisión de poder y con un imperativo de decidir lo mismo para casos semejantes $^{75}$, dejando a los demás juicios subjetivos de validez en una órbita externa al mismo derecho. Para el derecho, en su órbita interna, la única validez relevante será esta especie de "validez institucional" como juicio de contraste monopólico realizado por aquellos a los que el mismo ordenamiento ha entregado el poder o competencia para realizarlo ${ }^{76}$. En este escenario, solo este tipo de órganos pueden determinar que "la

${ }^{72}$ En este sentido, indica Guastini que "in un ordinamento come il nostro, dal "punto di vista esterno" [operadores diferentes a los que poseen poder de juzgar la validez], il sistema delle norme valide è semplicemente inconoscibile". GUASTINI (1992) p. 201.

73 No hay por qué imaginar que esta asignación de sentido variará sustancialmente de persona a persona. En efecto, el sentido natural de las palabras y nuestra misma pertenencia a un momento social y cultural específico, como también a un territorio determinado, nos hará coincidentes en muchos de los resultados. Sin embargo, ante normas abiertas (como las que consagran derechos fundamentales) aquel sentido natural de las palabras o aquellos arraigos podrán tambalear como argumentos unívocos y podrán mostrar divergencias sustanciales. Ante formas diversas de plantearnos nuestros planes de vida, diversas historias y, en fin, ante el hecho innegable de la diversidad, muy posible será nuestro disenso sobre la extensión de derechos básicos a situaciones prácticas.

${ }^{74}$ Kelsen (1942) p. 190. Y ello -como indica Atria- se da porque "el derecho es un sistema formal, es decir, un sistema elaborado sobre la base de una más o menos sofisticada red de competencias e incompetencias". ATRIA (2003) p. 321.

75 Este imperativo de juzgar de la misma manera los casos semejantes viene impuesto por el principio de igualdad formal, o de lo que Perelman denominó regla de justicia formal. Dentro del razonamiento jurídico, esta obligación encuentra sustento en el principio de universalidad o universalización, que consiste en que el juez que adopta una decisión en un caso concreto debe estar dispuesto a dar la misma solución a todos los casos futuros que se le presenten y que tengan análogas propiedades relevantes. Referido a un mismo aplicador del Derecho, esta regla de racionalidad se ha denominado "autoprecedente"., sobre la regla de justicia formal, Perelman (1964) pp. 28 y 55. Sobre la universalización, Alexy (1989) p. 187; MACCORMiCK (1997) p. 84-86; PRIETO (1992) pp. 163-169. Por último, sobre el autoprecedente GASCÓN (1993) pp. 37-38, y pp. 51-52.

${ }^{76} \mathrm{Y}$ aquí la norma competencial posee la misma validez (y jerarquía) que la norma que ha impuesto la jerarquía superior de la Constitución. Haciendo una síntesis entre ambas normas igualmente válidas podría concluirse la siguiente norma: Para el caso en que la jerarquía de la Constitución habilite la declaración de nulidad o derogación de una norma legal, solo el Tribunal Constitucional estará habilitado para declararla con los efectos señalados en la misma. 
norma X" es "inválida" (o nula), y en este enunciado "inválida” es usada en forma directa como juicio de validez de la norma ${ }^{77}$. En los demás casos, el predicado de "válida" no será ya usado sino solo mencionado entre comillas para hacer referencia (elípticamente) a un juicio ajeno a la validez misma de la norma ${ }^{78}$.

En este sentido, entonces, la nulidad representa la afirmación institucional de la imposibilidad de "reconocer" jurídicamente una norma "puesta" en el sistema ${ }^{79}$. Y este no reconocimiento se traducirá en una especie de prescripción dirigida a los órganos institucionales a efecto de prohibirles que hagan uso de la coacción estatal para ejecutar la prestación incluida en la norma considerada nula ${ }^{80}$. Su base no puede ser otra cosa que la ilegalidad. Lo ilegal -e incluyo aquí lo inconstitucional- no puede ser reconocido por el mismo sistema sin violentarse a sí mismo. Todo reconocimiento jurídico es, así, la legalidad misma. De ahí que cuando un sistema como el nuestro considera que los efectos pasados de una ley declarada inconstitucional son válidos -en tanto la inconstitucionalidad origina solamente la derogación de la ley- lo que hace es constitucionalizar los efectos pasados de aquella norma o, más bien, limitar constitucionalmente los efectos que podría imponer esa misma jerarquía si se le entendiese de manera absoluta y no racionalizada. Es entonces la misma Constitución la que, imponiendo su jerarquía (que no es otra cosa que su existencia como norma suprema), se encarga de racionalizar y optimizar la afectación de aquella jerarquía a las leyes, ya sea estableciendo recursos específicos para oponerla, plazos, tribunal competente o efectos de la declaración de inconstitucionalidad. Todo este cúmulo de regulaciones y restricciones representan, de igual modo, la constitucionalidad misma.

La idea de un específico sistema institucional de distribución de la constitucionalidad no puede, así, deducirse espontáneamente de la afirmación de la jerarquía normativa de la Constitución. De ella se deducirá, a lo más, que los actos contrarios a ella serán nulos en nuestro primer sentido. Pero, igualmente nulas (en términos de validez sistémica) serán las actuaciones judiciales que la contravengan.

Lo relevante, no será, entonces, aquella específica regla de nulidad, sino cómo, y, principalmente, quién queremos que institucionalmente declare la disconformidad, es decir, quién queremos que determine los complejos elementos de la tarea del contraste entre normas. Lo relevante será, al final, el poder asignado a un órgano del Estado de decir qué es lo que el derecho dice ${ }^{81}$. Esta es la gran decisión que los participantes en la creación de la Constitución deben tomar: quién queremos que diga lo que la Constitución dice. La misma decisión la hemos tomado ya para otras cuestiones, como por ejemplo quién queremos que decida las cuestiones relativas a materias sobre competencia, sobre familia, sobre juicios políticos, etc. Y esta misma decisión es la que hemos adoptado -al igual

\footnotetext{
77 GUASTINi (1992) pp. 199-200.

78 GuAstini (1992) p. 200.

79 En este sentido invalidez como "la declaración de ilegalidad relevante realizada por el órgano constitucionalmente legitimado para ello”. NIETO (1994) p. 22.

80 NinO (1985) p. 205.

81 Tal como se indica en EE.UU., lo relevante en todo este debate es, como lo afirmó Marshall, the province and duty of the judicial departament, to say what the law is. AHUMADA (2005) p. 21.
} 
que muchos países- en el ámbito de la justicia constitucional: queremos que cuando la aplicación de la Constitución conlleve la supresión de las leyes aprobadas democráticamente por nuestro Congreso dicho juicio sea realizado por un tribunal especial, elegido de una forma particular y con determinadas competencias. Hemos decidido que este tipo de asuntos sean conocidos por el Tribunal Constitucional.

\section{LA SITUACIÓN DEL CONTROL DE CONSTITUCIONALIDAD CON ANTERIORIDAD A LA REFORMA}

El siguiente argumento bajo análisis es aquel que sostiene que la posibilidad actual que tendrían los jueces ordinarios de inaplicar preceptos considerados por ellos inconstitucionales no sería otra cosa que una confirmación de la situación jurídica existente con anterioridad a la reforma. En aquel momento -se sostiene- la Corte Suprema no tenía el monopolio de inaplicabilidad y, por ende, en el caso en que las partes no planteasen el recurso, el juez podía inaplicar aquellas leyes de manera directa ${ }^{82}$.

Salvo los casos en que los jueces ordinarios declaraban derogada una norma legal preconstitucional por ser esta contraria a la Constitución ${ }^{83}$, no conozco siquiera un caso específico en que jueces ordinarios hayan inaplicado un precepto legal ejerciendo aquella posibilidad que supuestamente poseían. Y menos aún conozco alguna sentencia de nuestra Corte Suprema que haya avalado una situación como esa.

Ríos enumera algunas sentencias en donde algunos jueces parecieran haber ejercido este tipo de competencias. Muchas de estas sentencias, sin embargo, no son más que ejercicios de interpretación de leyes "conforme a la Constitución" o desarrollos del complejo fenómeno de la aplicación directa de normas de derecho internacional. Sin embargo, en cualquier caso son evidentemente casos muy aislados no corregidos oportunamente por razones que desconocemos. De ninguna manera, por ello, representan una tendencia jurisprudencia ni es dable pensar que sean avalados ni por la Corte Suprema ni hoy por el Tribunal Constitucional. Es en cambio la -según Ríos- "penosa” declaración que hace la Corte Suprema en uno de los casos que el mismo autor cita la que precisamente refleja la opinión de la Corte en estos asuntos. "[L]os jueces -dice la Corte- no pueden sustraerse de la aplicación de determinada ley, que resulta pertinente al caso que deben resolver, no obstante que pudieran considerarla contraria con un precepto constitucional, sino cuando la respectiva inaplicabilidad por inconstitucionalidad haya sido reconocida y declarada por esta Corte Suprema..." 84.

\footnotetext{
${ }^{82}$ Ríos (2002) pp. 408 y ss; MARTínez (2006) pp. 465-466.

${ }^{83}$ Ríos (2002) pp. 412 y ss. Esto se basaba en el argumento simplista de que una norma posterior de mayor jerarquía deroga a la anterior. Dicho argumento, sin embargo, comenzó a evitarse por la Corte Suprema en la década de los 90. Paradigmática en este tema es la sentencia de 16 de septiembre de 1992, Rol No 16.868 de la Sociedad Benefactora y Educacional Dignidad. Sobre este tema, SAENGER (2003) pp. 439 y ss. Una excelente interpretación de la situación actual en materia de leyes preconstitucionales y nueva inaplicabilidad puede verse en VEGA y ZúNígA (2006) pp. 158 y ss.

${ }^{84}$ Énfasis añadido. Ríos (2002) p. 416. Hoy dicha remisión debe entenderse hecha al Tribunal Constitucional.
} 
Así las cosas, creo que es bastante fácil sostener que con anterioridad a la reforma de 2005, y salvo lo que indicábamos a propósito de la derogación de normas preconstitucionales, la Corte Suprema sí tenía el monopolio de la inaplicación de las leyes inconstitucionales ${ }^{85}$. Como hemos indicado más arriba (2), el sistema de justicia constitucional que imperaba en nuestro país -y así era prácticamente entendido por la totalidad de la doctrina ${ }^{86}$ - era un modelo concentrado, "de dualidad de judicatura", ejercido de forma principal por la Corte Suprema a través del recurso de inaplicabilidad y ocasionalmente por el Tribunal Constitucional.

\section{LOS EJEMPLOS COMPARADOS}

Otro de los argumentos que apoyaría la tesis de la concesión a los jueces nacionales del poder de inaplicar las leyes cuando tuviesen la certeza de la inconstitucionalidad de estas, es que esta sería la solución elegida en diversos sistemas comparados. Un ejemplo de aquello se encontraría en el caso del sistema de judicial review adoptado por la Unión Europea ${ }^{87}$. Lo mismo podría sostenerse en los casos alemán, italiano, peruano, colombiano argentino o mexicano.

Este argumento, sin embargo, tampoco resulta convincente. Como veremos, ni el sistema alemán ni el italiano apoyan dicha tesis. El sistema colombiano o peruano como otros latinoamericanos representan opciones totalmente alejadas y diversas a nuestro ordenamiento jurídico y, finalmente, el sistema de la Unión Europea es un modelo totalmente sui generis, no definido totalmente y no asimilable a estructuras de control de constitucionalidad nacionales. Pero, aún esforzándonos en compararlo, tampoco reflejan la tesis criticada.

\subsection{COlOmbia y Perú}

Solo a vía de ejemplo tomo el caso de Colombia y Perú de entre varios otros países que han optado por un modelo de control difuso de constitucionalidad.

Creo que no resulta posible comparar nuestro sistema de control de constitucionalidad con el instituido en Colombia o en Perú toda vez que no es que con las mismas normas, herramientas o historia esos países hayan llegado a una conclusión diversa de la nuestra. Si en ambos países - como en otros- se encuentra vigente un sistema de control difuso de normas, es decir, donde cualquier juez puede declarar la inaplicabilidad de las leyes, ello se ha debido a que así lo han decidido a lo largo de su vida constitucional y las normas que han creado no son otra cosa que la plasmación de esos acuerdos previos.

En efecto, en el caso de Colombia, ya en la reforma constitucional de 1910 se había establecido un amplio control jurisdiccional de constitucionalidad de las leyes y una acción popular para iniciarlo. De esta forma, la constitucionalidad podía ser distri-

85 Esto, con la excepción de la declaración de inconstitucionalidad de Decretos con fuerza de Ley al tenor del antiguo art. 82.3 CPR o de las declaraciones de inconstitucionalidad referidas en art. 82.5 de la misma CPR, competencias ambas ejercidas por el Tribunal Constitucional.

${ }^{86}$ Salvo escasísimas excepciones, por ejemplo, Ríos (2005b) pp. 389-418.

${ }^{87}$ Especialmente MARTíneZ (2006) pp. 465 y ss. 
buida por cualquier tribunal e incluso por cualquier funcionario público, y la Corte Suprema solo actuaba como última instancia, de la misma forma que en los casos de simple aplicación de leyes ${ }^{88}$. La reforma de 1945 amplió incluso más este control, toda vez que atribuyó también a la jurisdicción de lo contencioso administrativo la competencia para conocer de las demandas por inconstitucionalidad de los decretos dictados por el Gobierno que no tuvieran carácter o fuerza de ley. Recién con la Constitución de 1991 se crea en forma específica un Tribunal Constitucional con competencias de control abstracto ${ }^{89}$.

De ahí que el sistema colombiano se haya caracterizado, desde sus inicios - por lo demás pioneros en la órbita latinoamericana e incluso mundial- precisamente por ser un sistema de control constitucional que ha privilegiado el carácter difuso en su construcción ${ }^{90}$. No obstante, este sistema no es ajeno a constantes críticas. El hecho que cualquier autoridad pública pueda realizar un examen de constitucionalidad es visto por muchos autores como un exceso, requiriéndose contrariamente su limitación o racionalización. El deterioro en la seguridad jurídica que esto origina posee un peso mayor a la hipotética ventaja de una supremacía absoluta de la Constitución ${ }^{91}$.

En el caso de Perú, por otro lado, lo incorrecto de la tesis criticada se muestra más evidente. Como se sabe, el sistema de justicia constitucional peruano es relativamente moderno. De hecho, fue la carta de 1979 la que estableció por primera vez un modelo denominado dual de jurisdicción constitucional, el cual solo duraría hasta el quiebre del régimen democrático de $1992^{92}$. Así las cosas, será la carta de 1993, vigente en la actualidad, la que delineará en forma específica el modelo de justicia constitucional elegido por Perú. En este orden de ideas, es suficientemente claro lo que dispone el actual art. 138 de la Constitución cuando indica que "[e]n todo proceso, de existir incompatibilidad entre una norma constitucional y una norma legal, los jueces prefieren la primera. Igualmente, prefieren la norma legal sobre toda otra norma de rango inferior". La opción por un sistema de control difuso es absolutamente evidente. Al lado de este control difuso se encuentra, sin embargo, un Tribunal Constitucional con competencia para resolver de la acción de inconstitucionalidad, conocer en última y definitiva instancia las resoluciones denegatorias de las acciones de habeas corpus, amparo, habeas data y acción de cumplimiento y, finalmente, resolver los conflictos de competencia.

\footnotetext{
${ }^{88}$ LÖSING (2002) p. 312.

${ }^{89}$ Cifuentes (1997) p. 68.

${ }^{90}$ Hoy, el control constitucional abstracto de las normas jurídicas en sentido material y de las reformas constitucionales le compete exclusivamente a la Corte Constitucional, mientras que cualquier juez tiene competencia para ejercer un control constitucional concreto en dos eventos: a) por vía de la "excepción de inconstitucionalidad" y b) en casos de interposición de acciones de tutela. La Corte Constitucional, sin embargo, actúa en el ámbito de la acción de tutela como máximo tribunal de revisión, seleccionando discrecionalmente (al estilo del certiorari norteamericano) aquellas sentencias que considere pertinentes y adoptando una decisión final sobre el asunto.

${ }^{91}$ En este sentido, COPETE (1960) p. 224.

92 Un antecedente de la opción por el modelo difuso se encontraba en el Código Civil 1936 vigente hasta 1984. Su art. 22 indicaba que "[c]uando hay incompatibilidad entre una disposición constitucional y una legal se prefiere la primera”. La aplicación de esta norma fue, sin embargo, siempre tímida.
} 
Como puede observarse, los sistemas colombiano y peruano han optado ya de manera histórica, ya de manera expresa, por un sistema en el cual los jueces tienen facultades completas de inaplicación de las normas legales. Nada más diverso de lo que sucede en Chile, donde tanto su tradición constitucional como el sistema de justicia constitucional que ha diseñado, han consagrado y perfeccionado -siguiendo los pasos de Europa- un sistema totalmente concentrado.

El argumento analizado es, entonces, ineficaz, pues no es posible sostener que un sistema jurídico como el chileno posee un determinado sistema de justicia constitucional porque otros lo adoptan. El mismo argumento podría utilizarse al contrario con aquellos países que -con historias y culturas mucho más parecidas a las chilenas- han optado por los sistemas contrarios.

\subsection{ITALIA Y ALEMANIA}

Los casos de Italia y Alemania no son -como lo indica algún autor ${ }^{93}$ - ejemplos que apoyen el argumento del derecho comparado más arriba expuesto. Ambos casos representan, con algunos matices, el clásico modelo de justicia constitucional "europeo" en contra del norteamericano y la manifiesta opción por concentrar la decisión de inaplicar las leyes inconstitucionales.

En Italia, la relación entre los jueces ordinarios y el Tribunal Constitucional está claramente definida en la regulación del llamado guidizio in via incidentale. En virtud de este instituto, el juez a quo eleva una cuestión de relevancia constitucional que aparece en el juicio principal de que conoce para ante el juez de la constitucionalidad, que en Italia es la Corte Costituzionale. A lo largo de la jurisprudencia de la Corte, se ha tratado de precisar qué tipos de jueces a quo están habilitados para elevar el asunto, quién puede producir ese juicio incidental y qué características debe tener la cuestión constitucional para abrir el acceso al juicio ante la Corte Costituzionale.

Dentro de este tercer aspecto, uno de los requisitos que debe tener la cuestión es que sea relevante. El art.1 de la Ley Constitucional 1/1948 es claro en afirmar que "la questione di legittimità costituzionale di una legge o di un atto avente forza di legge della Repubblica rilevata d'ufficio o sollevata da una delle parti nel corso di un giudizio e non ritenuta dal giudice manifestamente infondata, è rimessa alla Corte costituzionale per la sua decisione". Como se observa, el juez no esta obligado a remitir la cuestión de constitucionalidad solo cuando esta sea manifiestamente infundada. En los demás casos, debe ser remitida siempre a la Corte. Lo que se exige, entonces, para dar lugar al envío de la cuestión presentada o surgida es que esta sea "razonablemente seria" ${ }^{4}$.

\footnotetext{
93 MARTÍNEZ (2006) p. 467

94 Barbera y Fusardo (2006) p. 385. En este sentido el art. 23 de la Ley de 11 marzo 1953, n. 87 "Norme sulla costituzione e sul funzionamento della Corte costituzionale" dispone lo siguiente: "Nel corso di un giudizio dinanzi ad una autorità giurisdizionale una delle parti o il Pubblico Ministero possono sollevare questione di legittimità costituzionale mediante apposita istanza, indicando: a) le disposizioni della legge o dell'atto avente forza di legge dello Stato o di una Regione, viziate da illegittimità costituzionale; b) le disposizioni della Costituzione o delle leggi costituzionali, che si assumono violate. L'autorità giurisdizionale, qualora il giudizio non possa essere definito indipendentemente dalla risoluzione della
} 
Cuando el juez tiene alguna duda sobre la constitucionalidad de una norma, cuando está totalmente seguro de ello o cuando se le presenta una petición razonablemente seria, su actitud debe ser siempre la misma: elevar esa cuestión ante la Corte Costituzionale para que sea esta -en tanto constitucionalmente competente- la que determine si la norma es constitucional o no ${ }^{95}$. La total certidumbre del juez a quo de que la norma es inconstitucional, o su "fundada duda" acerca de ello, son tratadas de la misma forma por el ordenamiento italiano. En ambas ocasiones el juez deberá limitarse, no obstante su claro convencimiento, a transmitir la consulta a la Corte y a resolver la petición formulada indicando que ella "no es manifiestamente infundada" y, como tal, debe ser elevada ${ }^{96}$.

Como indica Ruggeri y Spadaro, en el sistema incidental, el juez ordinario es un filtro que deja pasar a la Corte solo las cuestiones serias y no dilatorias: no casualmente ha sido definido como "el portero" de la Corte ${ }^{97}$. El control que realiza es entonces un control de relevancia, seriedad o razonabilidad de la cuestión de constitucionalidad de la ley con el único objeto de que lleguen a la Corte las cuestiones que ameriten una resolución de su parte. De ahí la manifiesta importancia de este control, toda vez que colabora con la Corte en una mejor y más eficiente distribución de la constitucionali$\operatorname{dad}^{98}$.

La regulación de este asunto en Alemania es bastante similar a las soluciones italianas. La Constitución alemana indica claramente que "si un tribunal considera" que una ley que debe aplicar en un asunto determinado es inconstitucional, entonces debe inmediatamente suspender el proceso para recabar la decisión del Tribunal Constitucional, ya federal si la ley lo es, ya del respectivo Land si la ley proviene de aquel99.

De la misma forma que el sistema italiano, el juez alemán cumple una función de control de la relevancia de la cuestión de constitucionalidad (Entscheidungserheblichkeit ${ }^{100}$. Pero más que eso, lo que se ha entendido que deben hacer los jueces ordinarios alemanes en estos casos es el ejercicio de un poder de verificación a priori o, más bien, un verdadero "ensayo acerca de la inconstitucionalidad de la ley" por el cual aquel juez que considera que una ley infringe la constitucionalidad debe explicar cómo una

questione di legittimità costituzionale o non ritenga che la questione sollevata sia manifestamente infondata, emette ordinanza con la quale, riferiti i termini ed i motivi della istanza con cui fu sollevata la questione, dispone l'immediata trasmissione degli atti alla Corte costituzionale e sospende il giudizio in corso".

${ }^{95}$ por todos, Zagrebelsky (1988) pp. 190 y ss; CiCCOnetTi (2001) p. 54 y ss; Sorrentino (1998) pp.

50 y ss, entre otros.

96 Ruggeri y SPADAro (2004) p. 189; CelotTo (2004) p. 69 y ss.

97 Celotto (2004) p. 189. Esta función de filtro es la que hace que el sistema italiano sea definido como un sistema mixto entre control abstracto y concreto.

${ }^{98}$ Dolso (2003) pp. 315 y ss.

99 Así, dispone el art. 100 GG que "[h]ält ein Gericht ein Gesetz, auf dessen Gültigkeit es bei der Entscheidung ankommt, für verfassungswidrig, so ist das Verfahren auszusetzen und, wenn es sich um die Verletzung der Verfassung eines Landes handelt, die Entscheidung des für Verfassungsstreitigkeiten zuständigen Gerichtes des Landes, wenn es sich um die Verletzung dieses Grundgesetzes handelt, die Entscheidung des Bundesverfassungsgerichtes einzuholen”.

100 MAUNZ y DÜRIG (2006) T. VI, art. 100. p. 30. 
aplicación hipotética de la norma contravendría la constitución, lo cual significa que debe evaluar los posibles resultados que dicha aplicación generaría. De ahí que aquel juez casi no debe tener dudas acerca de la inconstitucionalidad de la ley, pues debe efectuar un trabajo, en extremo arduo y razonado, con el cual muestre la inconstitucionalidad de la ley. Lo que se le pide no es que exhiba dudas, sino que precisamente tenga claridad en relación a que la ley debe ser declarada inconstitucional ${ }^{101}$. Solo en este caso debe elevar el asunto al Tribunal Constitucional respectivo, único órgano competente, no ya para ensayar la inconstitucionalidad, sino que precisamente para declararla ${ }^{102}$.

Es justamente a estos sistemas -y al austriaco sobre todo- al que Chile ha seguido desde los primeros ensayos legislativos y constitucionales, no al norteamericano ni al colombiano ni al peruano ni al argentino ni al mexicano.

Y la posición que tienen los jueces ordinarios en los sistemas alemán e italiano es bastante sencilla y no por eso menos importante. Los jueces son el filtro de las cuestiones de constitucionalidad. Ellos contrastan las consecuencias que una determinada interpretación de una ley puede ocasionar concretamente en un caso determinado, para así exhibir con mayor claridad la constitucionalidad o inconstitucionalidad de la misma. Su convencimiento de que la ley es contraria a la Constitución o la consideración de haber argumentos serios en una petición de una parte acerca de ello, es la primera etapa en este procedimiento de inaplicabilidad de las leyes que finalizará en la definitiva decisión del Tribunal Constitucional, único órgano capacitado para esto.

\subsection{UNIÓN EUROPEA}

Realizar una comparación entre el modelo nacional y el modelo de judicial review existente en la actualidad en la Unión Europea es una tarea tan dificultosa como desaconsejable. En efecto, la misma relación entre el ordenamiento jurídico comunitario y el de los estados miembros es un tema de bastante complejidad como para ser examinado bajo el prisma de los conceptos y categorías tradicionales que hasta la fecha se han generado en el Derecho, y que se encuentran vigentes hoy en la mayoría de los ordenamientos estatales ${ }^{103}$.

Así por ejemplo, la misma idea de norma superior con la cual construir el parámetro de constitucionalidad resulta ser bastante indeterminada a nivel europeo. Un análisis prima facie, por ejemplo, entrega una clara preeminencia a las normas establecidas en los tratados constitutivos ${ }^{104}$, que representan una especie de derecho constitucional comunitario $^{105}$. Sin embargo, incluso esta idea es continuamente cuestionada. Como se sabe, uno de los principios desarrollados por el Tribunal de Justicia de la Comunidades Euro-

101 En este preciso sentido avanzan las legislaciones comparadas. En el caso español, por ejemplo, la reciente modificación a la Ley Orgánica del Tribunal Constitucional de 2007 se encargó de precisar que el tribunal que pretende elevar una cuestión de inconstitucionalidad "deberá concretar la ley o norma con fuerza de ley cuya constitucionalidad se cuestiona, el precepto constitucional que se supone infringido y especificar o justificar en qué medida la decisión del proceso depende de la validez de la norma en cuestión” (art. 35.2)

102 SCHLAiCH (1982) p. 569.

103 BARENTS (2004) pp. 167 y ss.

104 Por todos, SCHWARZE (1992) p. 248.

105 La caída del proyecto de Constitución europea no contribuye, sin embargo, a clarificar este asunto. 
peas $(T J C E)$ es el de supremacía del derecho comunitario, principio no contenido en los tratados constitutivos, sino que más bien entendido como una necesidad del nuevo orden jurídico que los tratados crean. Así, tanto o más importantes en la Comunidad Europea han sido las normas desarrolladas por el Tribunal de Justicia, que las contenidas en los tratados constitutivos. Además, como bien han indicado algunos autores, desde los casos Stauder ${ }^{106}$ o Internationale ${ }^{107}$, al lado de aquellas normas constitucionales de los tratados constitutivos se encuentran también otras reglas, generadas a través de un proceso de reconstrucción crítica comparada de las tradiciones constitucionales comunes de los estados miembros ${ }^{108}$. Estas tradiciones han sido caracterizadas como las normas fundamentales de la constitución material de la UE por dos razones: primero, porque solo de esta forma pueden explicarse y justificarse jurídica y convincentemente tres grandes casos como Van Gend $\mathcal{E}$ Loos $^{109}$, Costa $^{110}$ e Internationale, que han construido jurisprudencialmente el actual sistema jurídico europeo actual sin un soporte inmediato en los tratados, y que se fundan en una cierta idea de Europa construida en torno a estas tradiciones constitucionales comunes de los estados miembros; y segundo, porque esta caracterización corresponde a la comprensión de la Constitución europea como un proceso de integración de las tradiciones constitucionales nacionales y de sus interpretaciones por parte de los tribunales nacionales ${ }^{111}$. Este grupo de normas, "descubiertas" jurisprudencialmente se colocan al lado de las reglas escritas e ingresan el parámetro de "constitucionalidad" del derecho comunitario. Así por ejemplo, el principio de protección de los derechos fundamentales es considerado por el TJCE como uno de los principios claves del derecho europeo, aun cuando este no se encuentra ni en las reglas de los tratados ni en las normas derivadas de ellos ${ }^{112}$.

El parámetro de legalidad (o constitucionalidad) comunitaria es, entonces, una materia en vías de definición ${ }^{113}$. Una multiplicidad de principios jurídicos ${ }^{114}$, la misma

106 Caso Stauder c. City of Ulm de 12 de noviembre de 1969 (C-29/69)

107 Caso Internationale Handelsgesellschaft c. Einfuhr-und Vorratsstelle für Getreide und Futtermittel de 17 de diciembre de 1970 (C-11/70).

108 MENÉNDEZ (2006) p. 159.

109 Caso Van Gend en Loos c. Nederlandse Administratie der Belastingen de 5 de febrero de 1963 (C-26/62).

110 Caso Flaminio Costa c. ENEL de 15 de julio de 1964 (C-6/64).

111 Fossum y MENÉNDEZ (2005) pp. 390 y ss. Estos autores agregan que el proceso de especificación de dichas tradiciones se ha verificado tanto mediante la ratificación de los tratados constitutivos y sus sucesivas reformas, como a través de las sentencias en que el TJCE ha llenado ciertos vacíos dejados por los tratados; es decir, ha creado o reconstruido jurisprudencialmente normas y principios para resolver ciertos casos. Sobre las tradiciones constitucionales comunes, véase además BENGOETXEA (1994) p. 72; LENAERTS (2003) pp. 874 y ss.; MÖLLERS (2004) pp. 129-139.

112 MenÉNDEZ (2006) p. 158.

113 Esto, tanto porque el Tratado por el cual se instituye una Constitución para Europa no ha sido ratificado y existen dudas razonables sobre si entrará o no en vigor, como porque la identificación de las tradiciones constitucionales comunes es un proceso reconstructivo no exento de dificultades. Se trata de un mínimo común denominador que puede no extenderse a todos los estados miembros, y que además, en tanto integrado por principios, el contenido de los mismos debe ser objeto de determinación y delimitación por parte del TJCE.

114 Un enfoque del derecho comunitario desde los principios que lo informan puede verse en SCHWARZE (1992) en el mismo sentido, Tridimas (1999); UsHER (1998). 
reconstrucción de las tradiciones comunes, y las normas de los tratados constitutivos van formando la cúspide más clara de la derivación de validez de las normas inferiores.

Pero yendo incluso más lejos, aún suponiendo la existencia de una cúspide normativa clara, también puede apreciarse que el efecto de la supremacía del derecho comunitario posee claras fisuras en su relación con los ordenamientos de los estados miembros, tal como lo veremos luego.

Este panorama refleja en gran parte el proceso de integración de la Unión Europea como un proceso no cerrado, en el cual las categorías normativas tradicionales piramidales no tienen cabida, y donde cada día se va reestructurando un nuevo sistema jurídico sin precedentes.

Sin embargo, aun con las prevenciones que hemos indicado, es posible examinar en el ordenamiento comunitario una construcción similar a la existente en países de justicia constitucional concentrada. En efecto, en lo relativo a los actos generados por las instituciones europeas -sujetos estos al derecho constitucional comunitario- Europa no ha optado por un sistema de control difuso en donde cada tribunal que aplique dichos actos (principalmente los tribunales ordinarios de los estados miembros) pueda anularlos o desconocerlos. Frente a estos casos, los estados miembros prefirieron un control jerárquico y concentrado. Así lo prescribe hoy el art. 230 del Tratado Constitutivo de la Comunidad Europea, cuando dispone que será el TJCE el que controlará la legalidad de los actos adoptados conjuntamente por el Parlamento Europeo y el Consejo, de los actos del Consejo, de la Comisión y del Banco Central Europeo que no sean recomendaciones o dictámenes, y de los actos del Parlamento Europeo destinados a producir efectos jurídicos frente a terceros.

Este control de legalidad comunitaria lo realizará el tribunal a través de diversas acciones. Una de ellas es el recurso de anulación, de fisonomía muy parecida al control abstracto de constitucionalidad. Sin embargo, para lo que nos interesa, es especialmente relevante el art. 234 del tratado en cuanto dispone que el TJCE (y solo él, por cuanto es una norma competencial) será competente para pronunciarse, con carácter prejudicial, entre otras: a) sobre la interpretación del presente Tratado; y b) sobre la validez e interpretación de los actos adoptados por las instituciones de la Comunidad y por el BCE. Ambos casos representan dos problemas a los que los jueces nacionales se enfrentan cuando deben aplicar una norma comunitaria en un caso concreto que conocen: cuál es la correcta interpretación de la norma comunitaria y si esa norma es válida o no ${ }^{115}$. Y el mecanismo utilizado para resolver estas dudas no es otro que el utilizado por los mismos Tribunales Constitucionales de la órbita europea, es decir, el reenvío del asunto al TJCE ${ }^{116}$.

115 Tesauro (2003) p. 288.

116 TeSAURo (2003) p. 288. La razón de este reenvío es definida por el mismo Tribunal: "In the context of article 177 [hoy art. 234], whose purpose is to ensure that community law is interpreted and applied in a uniform manner in all the member states, the particular objective of the third paragraph is to prevent a body of national case-law not in accord with the rules of community law from coming into existence in any member state". Caso Hoffmann-La Roche AG v. Centrafarm Vertriebsgesellschaft Pharmazeutischer Erzeugnisse de 24 de mayo de 1977 (C-107/76). 
No obstante ello, el derecho comunitario no obliga a los jueces a efectuar consultas si no existe una duda razonable acerca de la aplicación ${ }^{117}$. Nuevamente, de la misma forma que cuando hablábamos del requisito de seriedad o relevancia de la cuestión de constitucionalidad en los tribunales constitucionales alemán o italiano, aquí también los jueces ordinarios pueden no realizar el reenvío e interpretar directamente el derecho comunitario si este se les presenta como claro ${ }^{118}$, o si la cuestión que se les plantea es irrelevante o ya ha sido resuelta con anterioridad ${ }^{119}$. Estas posibilidades son especialmente relevantes en lo relativo a la interpretación del derecho constitucional comunitario. Si el sentido fijado por el TJCE en otras sentencias es ya una jurisprudencia consolidada, no es necesario presentar una nueva cuestión interpretativa.

Sin embargo, esta cuestión de legitimidad comunitaria también puede plantearse, como medida prejudicial, en el ámbito de lo dispuesto en la letra b) del art. 234 ya indicado, esto es, en lo relativo a la validez de los actos comunitarios. Y de la misma forma que en materia interpretativa, los jueces podrían no reenviar el asunto al TJCE. De ahí que cabría preguntarse: ¿puede, entonces, discutirse la validez de los actos comunitarios en su instancia de aplicación, es decir, en los tribunales de los estados miembros? Una respuesta positiva a esta pregunta estaría -aunque limitadamente, como hemos visto y como veremos a propósito de las relaciones UE/Estados miembros- en la línea referida por la doctrina que criticamos en orden a entender que el sistema de control difuso tiene aplicación en el ordenamiento comunitario, toda vez que el juez de un estado miembro podría declarar inválida una norma comunitaria cuando tenga "claridad", y no ya duda, acerca de su contradicción con el derecho constitucional comunitario. Y, en efecto, el referido art. 234 pareciera dar una respuesta positiva a esa pregunta.

Sin embargo, no es posible sostener que ello proceda de esa forma. En efecto, ya el art. 41 del Tratado Constitutivo de la Comunidad Europea del Carbón y del Acero, parte, como se sabe, de las Comunidades Europeas, prescribía expresamente que "[s]ólo el Tribunal [Tribunal de Justicia de la Comunidad] será competente para pronunciarse, con carácter prejudicial, sobre la validez de los acuerdos de la Alta Autoridad y del Consejo, en caso de que se cuestione tal validez en un litigio ante un tribunal nacional”. Esta norma, no obstante, no se repitió en la versión consolidada del Tratado Constitutivo de las Comunidades Europeas.

Sin embargo, gran parte de los autores ha considerado totalmente indeseable una interpretación que habilite a los jueces de cada país para invalidar (o inaplicar) normas comunitarias, por considerar esto una amenaza a la seguridad jurídica y a la aplicación

\footnotetext{
117 Tampoco les obliga cuando son jueces inferiores. Solo habría obligación -siempre que la norma se considere "inconstitucional"- respecto a los jueces cuyas sentencias no admiten otras posibilidades de revisión.

118 Lo cual es aplicación de la llamada teoría del "acto claro" (acte clair) popularizada por el Conseil d'Etat francés en diversas de sus decisiones. En el ámbito europeo caso CILFIT e Lanificio di gavardo SPA $c$. Ministero della sanitá el 6 octubre de 1982 (C- 283/81)

119 SCHERMERS y WAELBROECK (2001) pp. 57 y ss. En esta esfera interpretativa bien valga lo indicado por Martínez en su trabajo: MARTíNEZ (2005b) p. 78.
} 
uniforme del derecho comunitario ${ }^{120}$, es decir, las mismas consideraciones por las cuales Europa ha luchado siempre por un sistema de control concentrado de constitucionalidad. Como indica Arnull "tal como es aceptable para los tribunales nacionales tener poderes limitados para interpretar ellos mismos las normas del derecho comunitario, es también importante que determinadas normas sean declaradas inválidas por tribunales cuyas resoluciones sean tenidas como decisiones de autoridad por las instituciones políticas y los demás tribunales de los estados miembros..." 121 .

Pero no solo ha sido la doctrina la que ha alzado la voz en contra de aquella posible interpretación del art. 234, sino que ha sido la misma jurisprudencia la que ha entendido también que la invalidez de las normas comunitarias debe realizarse solo por el TJCE. Y ello ha sido así desde que el Tribunal comenzó a entender que la declaración de invalidez vía art. 234 (cuestión prejudicial) no solo tenía efectos relativos para el juez y las partes que intervienen en el proceso que motiva la cuestión, sino que dicha declaración afectaba a todos los jueces para casos semejantes ${ }^{122}$. Nuevamente, razones de seguridad jurídica y uniformidad del derecho así lo aconsejaban ${ }^{123}$.

Una vez entendido que el efecto de la declaración de invalidez vía art. 234 posee efectos erga ommes, esto es, los mismos efectos que la declaración de nulidad vía art. 230, resulta natural que el Tribunal de Justicia exija que ambas decisiones sean adoptadas concentradamente por él, y no por cada uno de los tribunales de los estados miembros.

Así las cosas, la discrecionalidad de los jueces inferiores operará solo en un sentido, es decir, solamente podrán no remitir el asunto al Tribunal de Justicia cuando no acojan la invalidez, pero cuando crean firmemente que la norma comunitaria debe declararse inválida, deberán obligatoriamente remitir el asunto ${ }^{124}$.

El TJCE fue totalmente claro en el sentido antes indicado cuando en el caso FotoFrost v--Hauptzollamt Lübeck-ost The Times indicó que "[l]os órganos jurisdiccionales

120 HartLey (2003) p. 289; ARNULL (1988) p. 125.

${ }^{121}$ ARNULL (1988) p. 126.

122 Un interesante análisis de esta evolución jurisprudencia puede verse en TOTH (1984) pp. 61 y ss. Vid también HARDING (1981) p. 101-102.

${ }^{123}$ En el caso International Chemical Corporation c. Amministrazione delle finanze dello Stato, el TJCE incorpora, en la parte resolutiva de su sentencia, la siguiente regla que curiosamente tiene tal nivel de generalidad que parece dirigirse a un verdadero destinatario universal. "La sentenza della Corte -dice el tribunal- che accerti, in forza dell'art. 177 del trattato, l'invaliditá di un atto di un'istituzione, in particolare di un regolamento del Consiglio o della Commissione, sebbene abbia come diretto destinatario solo il giudice che si è rivolto alla corte, costituisce per qualsiasi altro giudice un motivo sufficiente per considerare tale atto non valido ai fini di una decisione che esso debba emettere; poichè tale constatazione non ha tuttavia l'effetto di privare i giudici nazionali della competenza loro attribuita dall'art. 177 del trattato, spetta a tali giudici stabilire se vi sia interesse a sollevare nuovamente una questione già risolta dalla corte nel caso in cui questa abbia constatato in precedenza l'invalidita di un atto di un'istituzione della comunità. tale interesse potrebbe, in particolare, esistere qualora sussistessero questioni relative ai motivi, alla portata ed eventualmente alle conseguenze dell'invalidità precedentemente accertata". Caso International Chemical Corporation c. Amministrazione delle finanze dello Stato de 13 de mayo de 1981(C-66/80). los comentarios a esta sentencia en LABAYLE (1982) pp. 492 y ss y en BEBR (1981) pp. 483 y ss.

${ }^{124}$ Un completísimo trabajo sobre este tema puede verse en ADINOLFI (1997). 
nacionales cuyas decisiones son susceptibles de recurso jurisdiccional de Derecho interno pueden examinar la validez de un acto comunitario y, si no estiman fundados los motivos de invalidez que las partes invocan ante ellos, desestimar estos motivos concluyendo que el acto es plenamente válido. En cambio, los órganos jurisdiccionales nacionales sean o no susceptibles sus decisiones de recurso jurisdiccional de Derecho interno, no son competentes para declarar por sí mismos la invalidez de los actos de las instituciones comunitarias".

"Esta solución viene impuesta, en primer lugar, por la exigencia de uniformidad en la aplicación del Derecho comunitario. Las divergencias entre los órganos jurisdiccionales de los Estados miembros en cuanto a la validez de los actos comunitarios podrían, en efecto, comprometer la unidad misma del ordenamiento jurídico comunitario y perjudicar la exigencia fundamental de seguridad jurídica”.

"Se impone, en segundo lugar, por la necesaria coherencia del sistema de protección jurisdiccional establecido por el Tratado. Este ha instituido, en efecto, mediante sus artículos 173 [hoy art. 230] y 184 [241], por una parte, y 177[234] por otra, un sistema completo de tutela jurisdiccional y de procedimientos destinado a confiar al Tribunal de Justicia el control de la legalidad de los actos de las instituciones. Dado que el artículo 173[230] atribuye competencia exclusiva al Tribunal de Justicia para anular un acto de una institución comunitaria, la coherencia del sistema exige que el poder de declarar la invalidez del mismo acto, si se promueve ante un órgano jurisdiccional nacional, se reserve igualmente al Tribunal de Justicia" 125.

Así las cosas, y ya para poner fin a la argumentación de derecho comunitario, el problema final quedará entonces restringido a las relaciones entre las normas comunitarias y las normas estatales. ¿Puede cualquier juez de los estados miembros inaplicar una norma estatal por ser esta contraria a las normas comunitarias? Este problema se ha abordado desde la perspectiva de la forma en que se concretiza la primacía del derecho comunitario por sobre el estatal y de cómo se articula la llamada "aplicación directa del derecho comunitario". La solución a este problema comenzó en el caso Van Gend E Loos señalado precedentemente. En este caso, una empresa neerlandesa se opuso ante un tribunal de los Países Bajos a pagar ciertos derechos de aduana por la importación de un producto desde Alemania. Esta tasa aduanera estaba impuesta por el derecho estatal pero, según el derecho europeo, no podía exigirse. El TJCE zanjó la cuestión indicando que el derecho comunitario es directamente aplicable en la órbita nacional siempre que sus normas: 1) estén formuladas sin condiciones, 2) sean completas en sí mismas y 3) no precisen para su cumplimiento o eficacia otros actos de los Estados miembros o de las instituciones comunitarias. En resumen, las normas comunitarias producen efectos directos cuando sean claras, precisas e incondicionales. En estos casos el juez debe aplicar directamente la norma comunitaria y "desplazar" (o inaplicar si se prefiere) con ello el derecho nacional. Pero, para volver a nuestro tema, valga entonces preguntarnos, ¿es posible encontrar normas constitucionales formuladas sin condiciones, completas en sí

125 Caso Foto-Frost c.- Hauptzollamt Lübeck-ost The Times de 22 de octubre de 1987 (C-314/85). 
mismas y que no precisen para su cumplimiento otros actos legislativos? Y nuestra respuesta es claramente negativa. En resumen, para que el derecho comunitario se aplique directamente, sus normas deben ser claras, estrictas y deben contener específicamente las obligaciones impuestas, cosa que como sabemos está absolutamente ausente en las normas constitucionales, que son inherentemente ambiguas y abiertas

Sin embargo, y esto complejiza aún más nuestro objeto de estudio, tampoco está totalmente claro que las normas comunitarias deban primar totalmente sobre todas las normas de los Estados miembros ${ }^{126}$. Conocida ha sido la actitud de algunos tribunales constitucionales europeos que han entendido que el derecho comunitario no puede contravenir las estructuras básicas que protegen las constituciones de los Estados. Así, por ejemplo, se ha manifestado el Tribunal Constitucional alemán en los denominados casos Solange $I^{127}$, Solange $I I^{128}$, y sobre todo en el caso Maastricht ${ }^{129}$. Lo mismo ha sucedido en los casos EMU ${ }^{130}$, Tobacco advertisement ${ }^{131}$ o Banana ${ }^{132}$. La Corte Costituzionale italiana ha seguido también esta doctrina en los casos Frontini ${ }^{133}$ y Granital $^{134}$. Otros países europeos han adoptado también líneas argumentativas similares ${ }^{135}$. De esta forma, es la misma supremacía total del derecho comunitario la que es puesta en duda.

En conclusión, no resulta ser muy provechosa una comparación entre los sistemas de control de constitucionalidad nacional y comunitario. No obstante, aun realizando esta comparación, tampoco es efectivo que el sistema comunitario haya asumido un sistema de control difuso para la custodia de la "constitucionalidad comunitaria". Es más, su estructura apunta precisamente en un sentido opuesto, esto es, a concentrar las decisiones de validez de las decisiones de las instituciones comunitarias en un único tribunal. Y finalmente, tampoco es efectivo que por la vía de las cuestiones prejudiciales el ordenamiento comunitario entregue a los jueces de los estados miembros un poder para que, en caso de "certidumbre" acerca de la invalidez de una norma comunitaria, puedan ellos declararla.

\footnotetext{
126 De hecho algunos países como UK se han opuesto continuadamente a que un futuro tratado constitucional europeo contenga una cláusula general de primacía del derecho comunitario por sobre el nacional. 127 BVerfGE 37, 271. Solange, en el sentido de la utilización la expresión "en la medida en que" o "en cuanto que" (solange) relativizando así la supremacía total del derecho comunitario por sobre el derecho estatal.

128 BVerfGE 73, 339.

129 BVerfGE 89, 155

130 BVerfGE 97, 350

131 BVerfGE 95, 370

132 BVerfGE 102, 147.

133 Corte Costituzionale, sentenze no 173 del 1983

${ }^{134}$ Corte Costituzionale, sentenze no 170 del 1984

135 CRAig y BÚrCA (2003) p. 285 y ss.

136 La pasividad de la Corte Suprema norteamericana en el caso de los presos de Guantánamo es, por ejemplo, solo una muestra de este fracaso.
} 


\section{CONCLUSIONES}

Como se ha podido revisar, los argumentos esgrimidos para apoyar la tesis de que nuestra actual Constitución posibilita la inaplicación de las leyes por parte de los jueces ordinarios son incorrectos y, por ende, poco convincentes.

Las relaciones entre los jueces ordinarios y el Tribunal Constitucional no vienen dadas ni por el reconocimiento de la jerarquía normativa de la Constitución ni por preconizar una defensa irrestricta de los derechos fundamentales. Este tipo de relaciones, al contrario, debe ser construido expresamente a través del pacto constitucional a través de decisiones generadas democráticamente. Y en dicho pacto se tomarán en cuenta -tal como lo han hecho muchos otros países- los múltiples criterios que puedan servir para optimizar la satisfacción de las pretensiones tanto comunitarias como individuales. ¿Cual es el mejor sistema para cumplir este fin? Una respuesta a esta pregunta requiere una reflexión mucho mayor acerca de nosotros mismos, de nuestra historia y de nuestras perspectivas a futuro. Sin embargo, la defensa de los derechos fundamentales o el supuesto respeto a la Constitución no impone de por sí que sean los tribunales ordinarios los habilitados naturalmente para llevarla a cabo. Ejemplos del fracaso de esa custodia tenemos por $\operatorname{cientos}^{136}$ y no debemos mirar tampoco tan lejos para encontrarlos. El Legislativo también tiene su historia negra, pero mal que mal esta refleja nuestra propia historia de aciertos y desaciertos. Un Tribunal Constitucional, de componente técnico pero de elección por los órganos legitimados democráticamente, es una buena solución de transición, mientras esperamos una mejora en nuestra comunidad y comenzamos a tomarnos más en serio y más responsablemente la primacía de los acuerdos comunes o, lo que es lo mismo, de la democracia.

\section{BIBLIOGRAFÍA CITADA}

AdINOLFI, Adelina (1997): L'accertamento in via pregiudiziale della validità di atti comunitari (Milano, Giuffrè) $432 \mathrm{pp}$.

AHumada RuIZ, Marian (2005): La jurisdicción constitucional en Europa (Madrid, Civitas) $321 \mathrm{pp}$.

ALEXY, Robert (1989): Teoría de la argumentación jurídica. La teoría del discurso racional como teoría de la fundamentación jurídica (Madrid, Centro de Estudios Constitucionales) $346 \mathrm{pp}$.

ARnull, Anthony (1988): "National courts and the validity of Community acts", European Law Journal, No 13: pp. 125-131.

ATRIA, Fernando (2003): "El derecho y la contingencia de lo político", Doxa, No 26: pp. 319-345.

Barbera, Augusto y Fusardo, Carlo (2006): Corso di diritto pubblico (Bologna, Il Mulino $4^{\mathrm{a}}$ ed.).

BARENTS, Rene (2004): The autonomy of Community Law (The Haghe, Kluwer)

BEBR, Gerhard (1981): "Preliminary Rulings of the Court of Justice: Their Authority and Temporal Effect”, Common Market Law Review, Vol. 18: pp. 475-507. 
BengoetxeA, Joxerramon (1994): "Legal System as a Regulative Ideal", ARSP, Beiheft No 53: pp. 65-80.

Bertelsen RepetTo, Raúl (1969): Control de Constitucionalidad de la Ley (Santiago de Chile, Editorial Jurídica de Chile) 188 pp.

Blanco VAldÉS, Roberto L. (1998): El valor de la Constitución (Madrid, Alianza) 333 pp.

Cappelletti, Mauro y AdAms, John Clarke (1966): "Judicial Review of Legislation: European Antecedents and Adaptations", Harvard Law Review, No 79: pp. 12071224.

CARAVITA, Beniamino (1985): Corte "Giudice a quo" e introduzione del giudizio sulle leggi. La Corte costituzionale austriaca (Padova, CEDAM)

CelotTo, Alfonso (2004): La corte costituzionale (Bologna, Il Mulino) 127 pp.

CicconetTI, Stefano Maria (2001): Lezioni di giustizia costituzionale (Torino, Giappichelli) $127 \mathrm{pp}$.

Cifuentes Muñoz, Eduardo (1997): "La Justicia Constitucional en Colombia”, Anuario Iberoamericano de Justicia Constitucional, No 1: pp. 67-88.

Copete Lizarralde, Alvaro (1960): Lecciones de derecho constitucional (Bogotá, Lerner)

CrAig, Paul y BúrCA, Gráinne de (2003): EU Law (Oxford, Oxford University Press $3^{\text {a ed.) }}$

CRUZ Villalón, Pedro (1987): La formación del sistema europeo de control de constitucionalidad (1918-1939) (Madrid, Centro de Estudios Constitucionales) 474 pp.

Dolso, Gian Paolo (2003): Giudici e corte alle soglie del giudizio di costituzionalità (Milano, Giuffrè).

DORADO PORRAS, Javier (1997): El debate sobre el control de constitucionalidad en los Estados Unidos (Madrid, Dykinson) 148 pp.

FERnÁndeZ GonZÁLEZ, Miguel Ángel (2005): “Constitución y Casación: ¿De la falta de aplicación al monopolio constitucional?”, Estudios Constitucionales, No 3-1: pp. 97-118.

Fiamma Olivares, Gustavo (1991): "Acción constitucional de nulidad y legitimación activa objetiva", Revista de Derecho Público, No 49: pp. 91-98.

FISKE, John (1896): The Critical Period of American History 1783-1789 (Cambridge, The Riverside Press).

Fossum, John Erik \& MenÉndeZ, Agustín José (2005): “The Constitution's Gift? A Deliberative Democratic Analysis of Constitution Making in the European Union”, European Law Journal, Vol. 11, No 4: pp. 380-410.

GARCÍA DE ENTERRía, Eduardo (2006): La Constitución como norma y el Tribunal Constitucional (Madrid, Civitas 4a ed.) 325 pp.

GARGARELla, Roberto (1996): La Justicia frente al Gobierno (Barcelona, Ariel) 279 pp.

GASCÓN ABELLÁN, Marina (1993): La técnica del precedente y la argumentación racional (Madrid, Tecnos) 107 pp.

GUASTINI, Riccardo (1992): "L'illegitimità delle disposizioni e delle norme”, Analisi e diritto: pp. 175-201. 
Hamilton, Alexander, Madison, James y Jay, John (2004): El Federalista (Traduce. G. Velasco, Mexico D.F., Fondo de Cultura Económica 2a ed.) 430 pp.

HARDING, Christopher (1981): "The Impact of Article 177 of the EEC Treaty on the Review of Community Action”, Yearbook of European Law, No 1: pp. 93-113.

Hartley, Trevor C. (2003): The foundations of European Community law: An introduction to the Constitutional and Administrative Law of the European Community, (Oxford, Oxford University Press $5^{\mathrm{a}}$ ed.).

Huneeus, Jorge (1891): La Constitución ante el Congreso (Santiago de Chile, Imprenta Cervantes) $553 \mathrm{pp}$.

Kelsen, Hans (1928): "La garantie juridictionnelle de la Constitution (La Justice constitutionell)", Revue du Droit public et de la Science politique, No 2: pp. 197-257.

Kelsen, Hans (1942): "Judicial Review of Legislation: A Comparative Study of the Austrian and the American Constitution", The Journal of Politics, Vol. 4, No 2: pp. 183-200.

KELSEN, Hans (1984): "What is a legal act?", The American Journal of Jurisprudence, No 29: pp. 199-212.

LabaYle, Henri (1982): "La Cour de justice des Communautés et les effets d'une déclaration d'invalidité", Revue Trimestrielle de Droit Européen, pp. 484-510.

LENAERTS, Koen (2003): "Interlocking legal orders in the European Union and Comparative Law", International and Comparative Law Quarterly, Vol. 52, No 4 pp. 873-906.

LÖSING, Norbert (2002): La jurisdicción constitucional en Latinoamérica (Traduce. M. ANZOLa GIL, Madrid, Konrad-Adenauer/Dykinson) 362 pp.

MACCORMICK, Neil (1997): Legal Reasoning and Legal Theory (Oxford, Clarendon).

MARTínez Estay, José Ignacio (2005a): "El sistema europeo-continental de justicia constitucional", Estudios Constitucionales, Vol. 3-1: pp. 149-171.

MARTíneZ EsTAY, José Ignacio (2005b): "El sistema europeo-continental de justicia constitucional: el control de constitucionalidad en la Unión Europea”, Estudios Constitucionales, No 3-2: pp. 51-83.

MARTínez Estay, José Ignacio (2006): "Recurso de inaplicabilidad, Tribunal Constitucional y juez ordinario en la reforma constitucional”, Nogueira Alcalá, H. (ed.), La Constitución reformada de 2005, (Santiago de Chile, Librotecnia) pp. 457-472.

MAUnZ, Theodor \& DÜRIG, Günter (2006): Grundgesetz Kommentar (München, Beck).

MENÉndEZ, Agustín José (2006): "Some elements of a Theory of European Fundamental Rights”, Menéndez, A.J. \& Eriksen E. O. (ed.) Arguing Fundamental Rights, (Dordrecht, Springer).

MÖllERS, Christoph (2004): "The Politics of Law and the Law of Politics: Two Constitutional Traditions in Europe”, Eriksen, E. O., Fossum, J.E., \& Menéndez, A. (eds.) Developing a Constitution for Europe, (London, Routledge) pp. 129-139.

Nieto, Alejandro (1994): "Prologo" Beladiez Rojo, M., Validez y eficacia de los actos administrativos (Madrid, Marcial Pons).

Nino, Carlos Santiago (1985): La validez del derecho (Buenos Aires, Astrea) 248 pp. 
Perelman, Chaim (1964): De la Justicia (México D.F., Universidad Nacional Autónoma de México).

PRIETO SANCHÍS, Luis (1992): Sobre principios y normas. Problemas del razonamiento jurídico (Madrid, Centro de Estudios Constitucionales) 186 pp.

Ríos Álvarez, Lautaro (1988): "El Principio de supremacía de la Constitución y el Tribunal Constitucional”, Revista de Ciencias Sociales, No 32/33: pp.129-155.

Ríos Álvarez, Lautaro (2002): "El Control Difuso de Constitucionalidad de la Ley en la República de Chile”, Ius et Praxis, No 8-1: pp.389-418.

Ríos Álvarez, Lautaro (2005a): “Trascendencia de la reforma constitucional en la fisonomía y las atribuciones del Tribunal Constitucional", Estudios Constitucionales, No 3-1: pp. 73-95.

Ríos Álvarez, Lautaro (2005b): "El control difuso de constitucionalidad de la ley en Chile y en otros países de América”, Las dos caras de Jano (Valparaíso, Edeval).

Ríos Álvarez, Lautaro (2005c): “El nuevo Tribunal Constitucional”, Zúñiga Urbina, Francisco (Coord.). Reforma Constitucional (Santiago, LexisNexis).

Ross, Alf (1994): Sobre el Derecho y la Justicia (Buenos Aires, Eudeba 5a ed.) 468 pp.

Ruggeri, Antonio Spadaro, Antonio (2004): Lineamenti di Giustizia costituzionale (Torino, Giappichelli).

SAENGER, Fernando (2003): "Inaplicabilidad por inconstitucionalidad. Jurisprudencia 1980-2003", Estudios Constitucionales, No 1: pp. 401-486.

SChermers, Henry y WaelbroecK, Denis (2001): Judicial Protection in the European Union, (The Hague, Kluwer Law International 6a ed.)

SCHLAICH, Klaus (1982): "Corte costituzionale e controllo sulle norme nella Repubblica Federale di Germania”, Quaderni Costituzionali, No 3: pp. 557-592.

SCHWARZE, Jürgen (1992): European Administrative Law (London, Sweet \& Maxwell) 1547 pp.

SORRENTINO, Federico (1998): Lezioni sulla giustizia costituzionale (Torino, Giappichelli $2^{\mathrm{a}}$ ed.) $181 \mathrm{pp}$.

Soto Kloss, Eduardo (1988): "La invalidación de los actos administrativos en el Derecho Chileno”, Revista de Derecho y Jurisprudencia, No LXXXV: pp. 157- 167.

Soto Kloss, Eduardo (1996): Derecho Administrativo (Santiago de Chile, Editorial Jurídica de Chile).

Soto Kloss, Eduardo (2000): "La nulidad de derecho público de los actos estatales y su imprescriptibilidad en el derecho chileno", Ius Publicum, No 4: pp. 55-62.

Tesauro, Giuseppe (2003): Diritto Comunitario (Padova, CEDAM) 753 pp.

TOCQueville, Alexis de (2002): La democracia en América (Madrid, Alianza).

Tотн, A.G. (1984): “The Authority of Judgments of the European Court of Justice: Binding Force and Legal Effects", Yearbook of European Law, No 4: pp. 1-77.

TRIDIMAS, Takis (1999): The General principles of EC Law (Oxford, Oxford University Press).

UsHeR, John Anthony (1998): General Principles of EC Law (London/New York, Longman). 
VEGA, Francisco y ZúÑIGA, Francisco (2006): "El nuevo recurso de inaplicabilidad por inconstitucionalidad ante el Tribunal Constitucional. Teoría y práctica”, Estudios Constitucionales, No 4-2: pp. 135-174.

WheELER, Russell (1973): "Extrajudicial Activities of the Early Supreme Court", The Supreme Court Review, V. 1973: pp. 123-158.

WoOD, Gordon (1988): “The origins of Judicial Review “, Suffolk University Law Review, No 22: pp. 1293-1307.

WOOD, Gordon (1999): "The origins of Judicial Review Revisited or How the Marshall Court Made More out of Less", Wash. \& Lee Law Review, No 56: pp. 787-809.

WoOD, Gordon (2003): La revolución norteamericana (Traducción de I. Merino, Barcelona, Mondadori) $250 \mathrm{pp}$.

WRÓBLEWSKI, Jerzy (1981): "Evaluative statements in law. An analytical approach to legal axiology”, Rivista Internazionale di Filosofia del Diritto, (IV Serie, LVIII): pp. 604-626.

ZagrebelsKy, Gustavo (1988): La guistizia costituzionale (Bologna, Il Mulino).

Zuñiga Urbina, Francisco (2002): Elementos de Jurisdicción Constitucional (Santiago de Chile, Universidad Central de Chile). 